\title{
Experimental determination of barium isotope fractionation during diffusion and adsorption processes at low temperatures
}

\author{
Kirsten van Zuilen ${ }^{\text {a, }}$, Thomas Müller ${ }^{\mathrm{b}}$, Thomas F. Nägler ${ }^{\mathrm{a}}$, Martin Dietzel ${ }^{\mathrm{c}}$ \\ and Tim Küsters ${ }^{b}$ \\ ${ }^{\text {a }}$ Institute of Geological Sciences, University of Bern, Baltzerstrasse 1+3, 3012 Bern, \\ Switzerland \\ ${ }^{\mathrm{b}}$ Institute of Geophysics and Tectonics, School of Earth and Environment, University of \\ Leeds, Leeds, LS2 9JT, UK \\ ${ }^{\mathrm{c}}$ Institute of Applied Geosciences, Graz University of Technology, Rechbauerstraße 12, \\ 8010 Graz, Austria
}

*Corresponding author: kirstenvanzuilen@gmail.com

Present address: Institut de Physique du Globe de Paris, 1 rue Jussieu, 75238 Paris cedex 05

Manuscript submitted to GCA on 22 September 2015

Revised manuscript submitted on 7 March 2016

$2^{\text {nd }}$ revised manuscript submitted on 22 April 2016

Keywords: Barium, Ba isotopes, diffusion, adsorption, stable isotope fractionation, experiment, diffusive transport model, reactive transport 


\section{Abstract}

Variations in barium $(\mathrm{Ba})$ stable isotope abundances measured in low and high temperature environments have recently received increasing attention. The actual processes controlling Ba isotope fractionation, however, remain mostly elusive. In this study, we present the first experimental approach to quantify the contribution of diffusion and adsorption on massdependent $\mathrm{Ba}$ isotope fractionation during transport of aqueous $\mathrm{Ba}^{2+}$ ions through a porous medium. Experiments have been carried out in which a $\mathrm{BaCl}_{2}$ solution of known isotopic composition diffused through u-shaped glass tubes filled with silica hydrogel at $10{ }^{\circ} \mathrm{C}$ and $25{ }^{\circ} \mathrm{C}$ for up to 201 days. The diffused Ba was highly fractionated by up to $-2.15 \%$ in $\delta^{137 / 134} \mathrm{Ba}$, despite the low relative difference in atomic mass. The time-dependent isotope fractionation can be successfully reproduced by a diffusive transport model accounting for mass-dependent differences in the effective diffusivities of the Ba isotope species $\left(D_{137_{B a}} / D_{134} B a=\left(m_{134} / m_{137}\right)^{\beta}\right)$. Values of $\beta$ extracted from the transport model were in the range of 0.010 to 0.011 . Independently conducted batch experiments revealed that adsorption of $\mathrm{Ba}$ onto the surface of silica hydrogel favoured the heavier Ba isotopes $(\alpha=1.00015 \pm 0.00008)$. The contribution of adsorption on the overall isotope fractionation in the diffusion experiments, however, was found to be small. Our results contribute to the understanding of $\mathrm{Ba}$ isotope fractionation processes, which is crucial for interpreting natural isotope variations and the assessment of $\mathrm{Ba}$ isotope ratios as geochemical proxies. 


\section{INTRODUCTION}

Barium $(\mathrm{Ba})$ has received attention in the past as geochemical proxy in both low and high temperature environments. In the oceans, precipitation of barite $\left(\mathrm{BaSO}_{4}\right)$, being the main carrier of particulate $\mathrm{Ba}$ in the water column, is associated with the decay of planktonic organic matter (Bishop, 1988; Dehairs et al., 1980; Ganeshram et al., 2003; Goldberg and Arrhenius, 1958). Consequently, export fluxes of $\mathrm{C}_{\text {org }}$ and $\mathrm{Ba}$ from the water column are positively correlated (Dymond and Collier, 1996; Dymond et al., 1992). Based on this correlation, $\mathrm{Ba}$ accumulation rates in marine sediments have been widely used to reconstruct paleo-productivities (e.g., Dymond et al., 1992; François et al., 1995; Hull and Norris, 2011; Paytan et al., 2007; Paytan and Griffith, 2007; Paytan and Kastner, 1996). The validity of this proxy, however, must be questioned for samples derived from sediments, where microbial sulphate reduction has taken place, as barite remains no longer stable (McManus et al., 1998; Paytan and Griffith, 2007).

Due to the flux of particulate Ba to the seafloor and hydrothermal activity (e.g., Cronan and Hodkinson, 1997; Dymond et al., 1992), Ba is strongly enriched in marine sediments relative to mid-ocean ridge basalt (MORB) (Plank and Langmuir, 1998). Subduction of these sediments, followed by extraction of $\mathrm{Ba}$ from the subduction slab into magmatic fluids, leads to Ba enrichment in the mantle wedge (Morris and Ryan, 2003). Thus, Ba has been used to trace subduction components in arc lavas (Elliott et al., 1997; Pearce and Stern, 2006; Plank and Langmuir, 1993, 1998) or recycled sediments in the mantle (Kuritani et al., 2011; Rapp et al., 2008).

The interest in mass-dependent $\mathrm{Ba}$ isotope fractionation in terrestrial (Bullen and Chadwick, 2016; Cao et al., 2016; Horner et al., 2015; Hsieh and Henderson, 2015; Kinsley et al., 2015; Miyazaki et al., 2014; Nan et al., 2015; Pretet et al., 2016) and extraterrestrial 
material (Moynier et al., 2015) has increased since the first Ba isotope study using multicollector inductively-coupled mass spectrometry (MC-ICP-MS) (von Allmen et al., 2010). For instance, $\mathrm{Ba}$ isotope fractionation might take place during magmatic processes, as indicated by variable Ba isotopic compositions of igneous rocks (Miyazaki et al., 2014; Nan et al., 2015). However, the observed isotopic variability in those rocks is relatively small $\left(<0.3 \%\right.$ in $\delta^{137 / 134} \mathrm{Ba}$; Nan et al., 2015). Larger Ba isotope fractionation is documented in low temperature environments (Bullen and Chadwick, 2016; Pretet et al., 2016; von Allmen et al., 2010). It was found that $\mathrm{Ba}$ in the ocean is isotopically heterogeneous (Cao et al., 2016; Horner et al., 2015; Hsieh and Henderson, 2015; Pretet et al., 2016), and Ba isotopes may, thus, prove to be a useful indicator for different water masses with distinct isotopic compositions (Horner et al., 2015). In addition, Ba isotopes may complement the existing $\mathrm{Ba}$ proxies, e.g., by validating the pelagic origin of barites found in marine sediments. Yet, the fractionation mechanisms causing the observed variations in $\mathrm{Ba}$ isotopic composition remain largely unknown. To date, it is only established that precipitating sulphates and carbonates preferentially incorporate the lighter Ba isotopes (Böttcher et al., 2012b; von Allmen et al., 2010). From other alkali and alkaline earth metals, however, we know additional processes and reaction mechanisms that can cause isotope fractionation, such as adsorption (Bolou-Bi et al., 2010; Hindshaw et al., 2013; Huang et al., 2012), complexation (Gussone et al., 2003; Rustad et al., 2010) or diffusion (Bourg et al., 2010; Chopra et al., 2012; Richter et al., 1999; Richter et al., 2006; Watkins et al., 2009).

Our study aims to quantify the fractionation of $\mathrm{Ba}$ isotopes by diffusive transport through a porous, surface-reactive medium at low temperatures. In nature, such transport of Ba ions takes place for instance in soils, sediments and sedimentary rocks. Classical natural microenvironments comprise of amorphous and jellylike inorganic structures, interrelated solid particles from micro- to nanoscale in aqueous media, e.g., clays and (hydr)oxides, and organic 
tissues and matrices, such as extracellular polymeric substances. We have designed a simplified experimental setup that will allow for diffusive transport through a silica hydrogel uniquely driven by a concentration gradient. The transport process is accompanied by sorption processes of $\mathrm{Ba}^{2+}$ onto reactive surface sites of the gel. Ba isotope fractionation factors related to mass-dependent differences in the isotopes' diffusivities and the impact of Ba adsorption on the overall fractionation are evaluated using transport diffusion models. The experimentally determined $\mathrm{Ba}$ isotope fractionation will provide crucial information to correctly interpret $\mathrm{Ba}$ isotope variations in nature.

\section{MATERIALS AND METHODS}

\subsection{Experimental setup}

Diffusion experiments were conducted in glass tubes with an inner diameter of $0.9 \mathrm{~cm}$. The u-shaped glass tubes were equipped with two reservoirs for source and sink, separated by a central part containing the silica hydrogel as porous medium at a centre distance of $10 \mathrm{~cm}$ (Fig. 1a). Silica hydrogel was freshly prepared from sodium silicate $\left(\mathrm{Na}_{2} \mathrm{SiO}_{3}{ }^{*} 9 \mathrm{H}_{2} \mathrm{O}\right)$ and hydrochloric acid $(\mathrm{HCl}) .13 .6 \mathrm{~g}$ of sodium silicate were dissolved in $50 \mathrm{ml}$ of de-ionized water, yielding a $\mathrm{pH}$ of 12.7. About $48.7 \mathrm{ml}$ of the sodium silicate solution were then stepwise admixed in increasingly smaller portions with a total of $40 \mathrm{ml}$ of $2 \mathrm{M} \mathrm{HCl}$ to reach a $\mathrm{pH}$ of 5.13. A volume of $9 \mathrm{ml}$ of the still liquid medium was immediately transferred into the glass tubes where it solidified overnight. The next day, the source and sink reservoirs of the glass tubes were filled with $5 \mathrm{ml}$ of $\mathrm{BaCl}_{2}$ solution $(\mathrm{pH} \sim 7)$ and de-ionized water $(\mathrm{pH} \sim 6)$, respectively, and tightly closed. $\mathrm{Na}^{+}$and $\mathrm{Cl}^{-}$ions were liberated during hydrolysis of the sodium silicate. Concentrations of both ions in the pore fluids of the solidified gel were estimated to be about $0.86 \mathrm{M}$ for all experiments. $\mathrm{Ba}^{2+}, \mathrm{Na}^{+}$and $\mathrm{Cl}^{-}$were present as free ions 
throughout the experiment, based speciation calculations using PHREEQC (Parkhurst and Appelo, 2013).

\section{[insert Fig. 1]}

A total of 40 single experiments were set up, divided into two separate series ( $G$ and $G 2$ ), which were started within 10 months of each other. The experimental series were designed with two defined initial $\mathrm{Ba}$ concentrations in the source $\left(0.1\right.$ and $1.0 \mathrm{M} \mathrm{BaCl}_{2}$, respectively) at two different temperatures $\left(10 \pm 0.1{ }^{\circ} \mathrm{C}\right.$ and $25 \pm 0.1{ }^{\circ} \mathrm{C}$, respectively), which were kept constant using water baths. The duration of the experiments were 2, 6, 12, 20 and 27 days, respectively, for series $\mathrm{G}$ and 20, 40, 61, 79 and 201 days, respectively, for series G2. After the defined run duration of each experiment, source and sink solutions were sampled completely by decanting the liquids in acid-cleaned sample tubes in order to ensure homogeneity of the reservoirs. It is assumed that no significant amounts of pore fluid from the gel compartment were admixed during sampling. The sample solutions were then acidified with distilled $\mathrm{HNO}_{3}$ to a $\mathrm{pH}$ of 2 and stored at $4{ }^{\circ} \mathrm{C}$ until analysis.

Isotope fractionation during adsorption of $\mathrm{Ba}$ onto the silica gel was determined by batch experiments. To that end, about $60 \mathrm{mg}$ of solidified, aged silica gel (stored at $4{ }^{\circ} \mathrm{C}$ for about 3 months) were weighed into pre-cleaned $1.5 \mathrm{ml}$ centrifuge vials. $1 \mathrm{ml}$ of $0.1 \mathrm{M}$ and $1.0 \mathrm{M}$ $\mathrm{BaCl}_{2}$ stock solution, respectively, was added and the vials were gently shaken. The batch experiments were allowed to react for 67 hours at room temperature. Subsequently, the dissolved Ba in the supernatant solutions ('ads_diss') were separated from the gel by centrifugation and sampled by careful pipetting, avoiding contamination by gel particles. The gel was then washed twice with $1 \mathrm{ml}$ MilliQ $\mathrm{H}_{2} \mathrm{O}$, centrifuged and the resulting wash solutions were collected for isotope analysis ('ads_wash-I' and 'ads_wash-II'). Finally, the gel was digested completely in $1 \mathrm{ml}$ of a 2:1 mixture of $28 \mathrm{M} \mathrm{HF}$ and $14 \mathrm{M} \mathrm{HNO}_{3}$ at $100{ }^{\circ} \mathrm{C}$ 
and taken to dryness. Fluorides that might have formed were subsequently dissolved in $1 \mathrm{ml}$ $6.4 \mathrm{M} \mathrm{HCl}$ at $130{ }^{\circ} \mathrm{C}$ and the samples were again allowed to dry.

\subsection{Sample preparation}

An aliquot of each sample amounting to $1 \mu \mathrm{g}$ of $\mathrm{Ba}$ was taken, mixed with an appropriate amount of ${ }^{130} \mathrm{Ba}^{135} \mathrm{Ba}$ double spike (von Allmen et al., 2010) and taken to dryness. Ba was purified from the sample's matrix by cation-exchange chromatography. Custom-made Teflon columns, accommodating a $4 \mathrm{~cm}$ long resin bed with an inner diameter of $6 \mathrm{~mm}$, were filled with $1.1 \mathrm{~cm}^{3}$ Dowex ${ }^{\circledR} 50 \mathrm{WX} 8$ (200-400 mesh) cation-exchange resin. After cleaning (10 ml of $6.4 \mathrm{M} \mathrm{HCl})$ and conditioning the resin $(4 \mathrm{ml} 2.5 \mathrm{M} \mathrm{HCl})$, the samples were loaded in $0.5 \mathrm{ml}$ of $2.5 \mathrm{M} \mathrm{HCl}$. Matrix elements were eluted with additional $7.5 \mathrm{ml}$ of $2.5 \mathrm{M} \mathrm{HCl}$. Finally, $\mathrm{Ba}$ was collected in $5 \mathrm{ml}$ of $6.4 \mathrm{M} \mathrm{HCl}$ and taken to dryness. Total procedure blanks were measured routinely over a period of 17 months, yielding an average below $0.5 \mathrm{ng} \mathrm{Ba}$.

\subsection{Analytical procedure for Ba isotope analyses}

Samples were redissolved in $0.5 \mathrm{M} \mathrm{HNO}_{3}$ to yield a concentration of natural $\mathrm{Ba}$ of $100 \mathrm{ppb}$ suitable for isotope analyses. Measurements were performed on a $\mathrm{Nu}$ Plasma $(\mathrm{Nu}$ Instruments) multi-collector inductively-coupled plasma mass spectrometer (MC-ICP-MS) at the University of Bern, equipped with an ESI Apex Q sample introduction system. Signals of ${ }^{130} \mathrm{Ba}^{+},{ }^{134} \mathrm{Ba}^{+},{ }^{135} \mathrm{Ba}^{+}$and ${ }^{137} \mathrm{Ba}^{+}$were simultaneously detected together with ${ }^{125} \mathrm{Te}^{+}$and ${ }^{129} \mathrm{Xe}^{+}$ to correct for isobaric interferences (von Allmen et al., 2010). Xe-interference contributions to

${ }^{130} \mathrm{Ba}$ and ${ }^{134} \mathrm{Ba}$ were calculated using isotope ratios published by IUPAC (de Laeter et al., 2003) that were corrected for instrumental mass bias using the exponential fractionation law. Interferences of Te were below detection limit and have been thus neglected. Data collection consisted of 10 blocks of 10 cycles with $5 \mathrm{~s}$ integration time. An electronic baseline $(10 \mathrm{~s}$ 
integration time) was measured prior to each block. A Faraday gain calibration was performed weekly. Instrumental mass bias was corrected for by the ${ }^{130} \mathrm{Ba}-{ }^{135} \mathrm{Ba}$ double spike. The measured raw data were reduced using the iterative solution of Compston and Oversby (1969). However, the exponential fractionation law was used instead of the linear one.

All data are reported relative to NIST SRM 3104a using the delta-notation in per mill (\%):

$$
\delta^{137 / 134} B a=\left(\frac{{ }^{137} B a /{ }^{134} B a_{\text {sample }}}{{ }^{137} B a /{ }^{134} B a_{\text {SRM } 3104 a}}-1\right) \cdot 1000
$$

The intermediate measurement precision of sample analyses was estimated by calculating the pooled standard deviation of all repeated measurements to be $\pm 0.09 \%$ o $\left(2 \mathrm{~s}_{\mathrm{p}}\right)$ on $\delta^{137 / 134} \mathrm{Ba}$. This is in excellent agreement with repeated measurements of the Fluka Aldrich $\mathrm{Ba}\left(\mathrm{NO}_{3}\right)_{2}$ ICP-OES standard solution used in von Allmen et al. (2010) over the course of eight months, yielding a $\delta^{137 / 134} \mathrm{Ba}$ value of $0.02 \pm 0.09 \%$ o $(2 \mathrm{sd} ; \mathrm{n}=42)$.

Ba concentrations of the samples were determined by isotope dilution simultaneously with the $\mathrm{Ba}$ isotopic composition. For this purpose, the concentration of ${ }^{135} \mathrm{Ba}$ in the double spike was first determined by inverse isotope dilution using the NIST SRM 3104a $\left(10.014 \pm 0.036 \mathrm{mg} \mathrm{g}^{-1} \mathrm{Ba}\right.$ in total) to be $18.77 \pm 0.18 \mathrm{nmol} \mathrm{g}^{-1}$.

\section{RESULTS}

\subsection{Diffusion experiments}

In all experiments, the Ba concentration in the source systematically decreased with time while the Ba concentration in the sink increased (Fig. 2). The observed diffusive flux of Ba correlates positively with temperature and initial Ba concentration in the source. The monitored concentration data in source and sink of series G2 after 20 days agree well with the Ba concentration in the two reservoirs of series $\mathrm{G}$ after the same experimental run duration. Although two batches of silica hydrogel were separately prepared for the two experimental 
series, the agreement in Ba concentration after 20 days suggests that the properties of the prepared gels that influence the effective diffusivity through the gel, such as porosity and tortuosity, were comparable.

\section{[insert Fig. 2]}

\section{[insert Table 1]}

The measured $\delta^{137 / 134} \mathrm{Ba}$ values of the initial $\mathrm{BaCl}_{2}$ solutions vary slightly within the analytical uncertainty (Table 1). For the following discussion, the isotopic compositions of source and sink reservoirs are, thus, further expressed as $\Delta^{137 / 134} \mathrm{Ba}_{\text {sink/source }}=$ $\delta^{137 / 134} \mathrm{Ba}_{\text {sink/source }}-\delta^{137 / 134} \mathrm{Ba}_{\text {initial }}$, with $\delta^{137 / 134} \mathrm{Ba}_{\text {inital }}$ corresponding to the respective initial $\mathrm{BaCl}_{2}$ solution $(0.1$ or $1.0 \mathrm{M})$ of the experimental series $\mathrm{G}$ and $\mathrm{G} 2$. The measured $\mathrm{Ba}$ isotopic composition of the source of all four experimental series was indistinguishable from the initial $\mathrm{BaCl}_{2}$ solution within the first 27 days, suggesting a slight increase thereafter, but still within analytical uncertainties over the experimental run time (Fig. 2). In contrast, the measured isotope ratios of the fluid from the sink reservoirs were depleted in the heavy Ba isotopes by up to $-2.30 \%$ in $\Delta^{137 / 134} \mathrm{Ba}_{\text {sink }}$ after 6 days (Table 1), representing the lowest $\delta^{137 / 134} \mathrm{Ba}$ value documented so far in the literature (i.e., $-2.15 \pm 0.08 \%$ o). The $\Delta^{137 / 134} \mathrm{Ba}$ values increased rapidly and tended towards zero with progressive run durations of the experiments. Like the Ba concentration data, the isotopic compositions of the source and sink reservoirs after 20 days were, within the analytical uncertainties, identical for the two series G and G2.

\subsection{Batch experiment}

Silica hydrogel is known to have a large, reactive surface. At $\mathrm{pH}$ values above the point of zero charge (PZC), which is around 3 in case of silica hydrogel (Bolt, 1957), the gel surface is negatively charged, allowing adsorption of cations. Our experiments were conducted at $\mathrm{pH}>5$, so that adsorption of $\mathrm{Ba}^{2+}$ onto the gel surface is expected. The batch experiments 
showed that adsorption of $\mathrm{Ba}$ onto the silica hydrogel results in significant isotope fractionation. The adsorbed Ba ('ads_gel') is enriched in the heavy Ba isotopes by 0.12 to $0.17 \%$ in $\delta^{137 / 134} \mathrm{Ba}$ relative to the dissolved $\mathrm{Ba}$ (Table 2). The equilibrium isotope fractionation factor $\alpha$ can be defined as

$$
\alpha=\frac{\delta^{137 / 134} B a_{\text {adsorbed }}+1000}{\delta^{137 / 134} B a_{\text {dissolved }}+1000}
$$

and was accordingly calculated to be $1.00012 \pm 0.00006$ for $0.1 \mathrm{M} \mathrm{BaCl}_{2}$ and $1.00017 \pm$ 0.00002 for $1.0 \mathrm{M} \mathrm{BaCl}_{2}$, yielding an average value of $1.00015 \pm 0.00008$ ( $\left.2 \mathrm{sd}\right)$. The $2 \mathrm{sd}$ uncertainties of the single experiments were determined using Monte Carlo simulations. The experimental design of the batch experiments came with the unavoidable effect that some dissolved Ba remained in the pore spaces of the gel. Therefore, two washing steps were carried out after sampling of the supernatant solution. Importantly, Ba might have been desorbed from the gel either by the washing procedure or by aging of the silica hydrogel, causing a decrease in surface area (see discussion below). However, the isotopic compositions of $\mathrm{Ba}$ in the wash solutions were identical to that of the dissolved $\mathrm{Ba}$, indicating that no significant amounts of Ba were desorbed from the gel.

\section{[insert Table 2]}

The total amount of $\mathrm{Ba}$ adsorbed onto the silica hydrogel during the batch experiments with $0.1 \mathrm{M}$ and $1.0 \mathrm{M} \mathrm{BaCl}_{2}$ were determined to be 2.1 and $7.7 \mathrm{mg}$ per $\mathrm{ml}$ gel, respectively. Translated to the diffusion experiments using a total of $9 \mathrm{ml}$ silica hydrogel, the maximum amounts of adsorbed Ba can be estimated to be 19 and $69 \mathrm{mg}$, yielding about 29 and $10 \%$, respectively, of the total introduced $\mathrm{Ba}$.

\section{DISCUSSION}

\subsection{Diffusive isotope effects}


The migration rate of different elements or isotopes through a given medium is affected by their mass, which can result is subtle fractionation induced by the diffusive transport (Richter et al., 2003). The ratio of the effective diffusion coefficients of two isotopes $D_{1}$ and $D_{2}$ of one chemical element is related to the ratio of their molecular masses $m_{1}$ and $m_{2}$ and can be expressed as an inverse power-law function:

$$
\frac{D_{1}}{D_{2}}=\left(\frac{m_{2}}{m_{1}}\right)^{\beta}
$$

This expression is based on studies of low density gases at low pressures (i.e., virtually no interaction between single atoms or molecules) for which the relative diffusivities are simply inversely proportional to the square root of their mass $(\beta=0.5)$. In two seminal studies, Richter et al. (2003); Richter et al. (1999) placed this concept into a geologically relevant context of diffusion in molten silicates. Melt structures are complex and, thus, the square root relation was replaced by an empirical exponent. This dimensionless exponent $\beta$ can be determined either experimentally (Bourg et al., 2010; Richter et al., 2006) or by molecular dynamics (MD) simulations (Bourg et al., 2010; Bourg and Sposito, 2007). Values of $\beta$ are highest $(<0.22)$ for elements diffusing through silicate melts (Richter et al., 2003; Richter et al., 2009; Richter et al., 2008; Watkins et al., 2009; Watkins et al., 2011) and for non-ionic species in water (Bourg and Sposito, 2008). For ions diffusing in liquid water, however, $\beta$ is considerably smaller $(<0.05)$ (Bourg et al., 2010). The reasons for this are substantial interactions of the solute with the solvent. In case of silicate melts, $\mathrm{Si}$ and $\mathrm{O}$ are strongly bound in multi-atom complexes, and a solute diffuses faster than the main matrix elements (Watkins et al., 2011). In aqueous solutions, however, water molecules are bound to diffusing ions, forming hydration shells. It has been found that $\beta$ is inversely correlated with the residence time $\left(\tau_{S}\right)$ of water molecules in the first solvation shell (Bourg et al., 2010). $\tau_{S}$ is longer for divalent cations, such as $\mathrm{Ca}^{2+}$ and $\mathrm{Mg}^{2+}$, than for monovalent ions because of a strong solute-solvent attraction interaction (Bourg et al., 2010). Therefore, alkaline earth 
metals show little isotope fractionation by ion diffusion in liquid water (Bourg et al., 2010; Bourg and Sposito, 2007; Richter et al., 2006).

\subsubsection{Diffusive transport model}

We used an implicit finite difference model in one dimension to solve simultaneously for the diffusive migration of ${ }^{134} \mathrm{Ba}$ and ${ }^{137} \mathrm{Ba}$ (denoted by $i$ ) following Fick's first law (note that all other isotopes are ignored for simplicity):

$$
J_{i}=-\phi \tau D_{i} \frac{\partial n_{i}}{\partial x}
$$

In this equation the diffusive flux is governed by the porosity $(\Phi)$, the tortuosity $(\tau)$, the diffusion coefficient of each species $\left(D_{i}\right)$ and the concentration gradient $\left(\partial n_{i} / \partial x\right)$. The geometry of the model system divides the one-dimensional column into three parts comprising the sink, the silica hydrogel reservoir and the source. The spacing for the numerical calculation was set to $1 \mathrm{~mm}$, resulting in 79 nodes for each the sink and the source (the length of the sink and source reservoirs equal $\sim 7.9 \mathrm{~cm}$, as determined by a volume of $5 \mathrm{ml}$ solution applied in the experimental tube with an inner diameter of $0.9 \mathrm{~cm}$ ) and 141 nodes for the length of the silica gel reservoir (corresponds to $9 \mathrm{ml}$ of gel) (Fig. 1). The model system is assumed to behave as a closed system with no-flux boundaries on both ends. It allows for spatial variations of the effective diffusion coefficients in order to simulate different behaviour in the different reservoirs as will be discussed later.

\section{[insert Fig. 3]}

Initially, the reservoirs containing the silica gel and the sink are Ba-free, while the source contains a defined number of moles of each Ba species being homogeneously distributed in the source. With time, Ba diffuses from the initially homogeneous source reservoir through the region filled with silica gel into the sink reservoir, developing the typical diffusion-type transient shape (Fig. 3a). Diffusion coefficients of ${ }^{134} \mathrm{Ba}$ were set to higher values compared 
with ${ }^{137} \mathrm{Ba}$, resulting in low $\Delta^{137 / 134} \mathrm{Ba}$ values in sink and gel, as shown by time-resolved spatial profiles along the model geometry (Fig. 3b). At the same time, the residual source becomes enriched in the more slowly diffusing ${ }^{137} \mathrm{Ba}$. The predicted spatial variations in isotopic composition decrease with time as the Ba concentration in the closed system homogenises, erasing the existing mass-dependent fractionation signature (Fig. 3b). Thus, subtle differences of the effective diffusion coefficients of the different isotope species lead to kinetically controlled spatial isotope fractionation according to Eq. 5.

\subsubsection{Data fit}

In the further discussion, the $1.0 \mathrm{M} / 10{ }^{\circ} \mathrm{C}$ diffusion experiment will be used as an example for the model fit. The three other experimental series conducted at a different temperature and/or with a different initial $\mathrm{BaCl}_{2}$ concentration are fitted comparably well by the diffusive transport model (see Supplement). Modelled Ba concentrations in sink and source were integrated over the respective reservoir at a given time, and the effective diffusion coefficients (Table 3) were determined by fitting the modelled data to the measured Ba concentrations of the sink (Fig 4d). The extracted effective diffusion coefficients were then assigned to the more abundant ${ }^{137} \mathrm{Ba}$ and the relative difference for the migration speed of ${ }^{134} \mathrm{Ba}$ was simulated by adjusting $\beta$ in Eq. 3 to fit the isotopic composition measured in the sink reservoir over the experimental runtime (Fig. 4f).

\section{[insert Fig. 4]}

The time-dependent change in concentration of the Ba species $\left(\partial n_{i} / \partial t\right)$ diffusing through the silica hydrogel is affected by porosity $(\phi)$, tortuosity $(\tau)$ and adsorption of Ba at the gel $\operatorname{surface}\left(n_{i}^{a d s}\right)$ :

$$
\frac{\partial n_{i}}{\partial t}=-\phi \tau \frac{\partial}{\partial x}\left(D_{i} \frac{\partial n_{i}}{\partial x}\right)-n_{i}^{a d s}
$$


In theory, one can determine the tortuosity of the system when both the porosity and the diffusion coefficient are well constrained and the concentration gradients are known. The porosity of the silica hydrogel used in this study was determined by drying and reweighing of a defined volume of the gel to be $0.98 \pm 0.03$ ( $2 \mathrm{sd})$. The tortuosity should be equally close to unity for such high porosities. We, therefore, do not feel confident to separate both effects for our experimental setup and treat them as factor $u=\phi^{*} \tau$. For the present experimental setup, small deviations from unity $(u=0.95)$ are assumed. The overall effect of porosity and tortuosity is illustrated by adjusting the diffusive flux in the silica gel bearing reservoir using values for $u$ from 0.5 to 1 (Fig. 5). Diffusivities in the source and sink have been held constant (with $u=1$ ). Lower values for $u$, denoting a decrease in the effective diffusive flux within the silica hydrogel, do not influence the predicted evolution of Ba concentration in the sink and only slightly improve the data fit in the source (Fig. 5). However, they require higher diffusion coefficients to fit the measured Ba concentration data.

\section{[insert Fig. 5]}

The modelled effective diffusion coefficients for $u=0.95$ are comparable to published salt diffusion coefficients for $\mathrm{BaCl}_{2}$ in aqueous solutions (Robinson and Stokes, 2002; Table 3). For the experiments with $1.0 \mathrm{M} \mathrm{BaCl}_{2}$, however, they are systematically higher than published values, whereas diffusion coefficients for experiments with $0.1 \mathrm{M} \mathrm{BaCl}_{2}$ are systematically lower, but closer to the data of Robinson and Stokes (2002) (Fig. 6). Further, the diffusion model successfully reproduces the time-dependent change in the sink phase for both the total Ba concentration (Fig. 4b) and the measured isotopic composition (Fig. 4f). However, the predicted evolution of the source reservoir does not match the measured concentrations (Fig. 4a). In all modelled scenarios (see also in the Supplement) the measured Ba concentrations systematically decrease more rapidly in the source reservoir than predicted 
by the simple diffusion model. This suggests a higher outflux of $\mathrm{Ba}$ from the source reservoir into the gel in the initial stages of the experiment.

\section{[insert Fig. 6]}

\section{[insert Table 3]}

In mixed electrolyte solutions, diffusion of an ion is affected by the electric fields generated by the other diffusing ionic species (e.g., Leaist and Curtis, 1999; Steefel and Maher, 2009). Thus, we have to consider multicomponent diffusion of $\mathrm{BaCl}_{2}$ and $\mathrm{NaCl}$, the latter being present in the pore fluids of the silica hydrogel with initial concentrations of about $0.8 \mathrm{M}$, with opposite concentration gradients between source and gel compartment. Multicomponent diffusion was modelled using PHREEQC (Parkhurst and Appelo, 2013), described in detail in the Supplement. The model indicates that multicomponent diffusion only affects the effective diffusivity of $\mathrm{Ba}$ in the $1.0 \mathrm{M} \mathrm{BaCl}_{2}$ experiments and that it negligible for the $0.1 \mathrm{M}$ experiments. This is in agreement with the observation that the diffusion coefficients extracted from the numerical transport model for the $0.1 \mathrm{M} \mathrm{BaCl}_{2}$ experiments are very close to the published salt diffusion coefficients of $\mathrm{BaCl}_{2}$ in pure water. Furthermore, the PHEEQC simulation predicts higher effective Ba diffusivities for the $1.0 \mathrm{M}$ $\mathrm{BaCl}_{2}$ experiments, which is again in agreement with the higher diffusion coefficients needed in our numerical solution to fit the measured concentrations in the sink reservoir compared to literature.

However, comparison of the spatially integrated amount of $\mathrm{Ba}$ in the source after 20 days (453 mg Ba) with the measured value from the $1.0 \mathrm{M} / 25^{\circ} \mathrm{C}$ experiment (357 mg Ba) suggests that enhanced fluxes due to multicomponent diffusion alone is insufficient to explain the observed deviation between our numerical model and the experimental data. In addition, the multicomponent effect can only be expected to vanish when approaching complete homogenisation of the system, which is in disagreement with the convergence of the 
modelling results and the experimental data after 20 days while significant concentration gradients were still present. We therefore suggest that the effect of multicomponent diffusion is likely to be compensated by using a higher effective diffusion coefficient, justifying the use of a simple one-component diffusion model for the purpose of this study.

At the beginning of the diffusion experiment, differences in density existed between the $\mathrm{BaCl}_{2}$ solutions in the source (1.018 and $1.171 \mathrm{~g} \mathrm{~cm}^{-1}$ for $0.1 \mathrm{M}$ and $1.0 \mathrm{M} \mathrm{BaCl}_{2}$, respectively, at $25{ }^{\circ} \mathrm{C}$; Puchalska and Atkinson (1991)) and the deionised water in the sink reservoir $\left(0.997 \mathrm{~g} \mathrm{~cm}^{-1}\right.$ at $\left.25^{\circ} \mathrm{C}\right)$. Due to the vertical alignment of the source and sink reservoirs, these density differences were most likely compensated by a short-lived, local advective flux component from the source into the gel reservoir, resulting in a net increase of the observed effective diffusion coefficient, as demonstrated by Debacq et al. (2003). This effect could explain both the lower measured Ba concentrations in the source compared to the model and the higher effective diffusion coefficients for the $1.0 \mathrm{M} \mathrm{BaCl}_{2}$ experiments compared to Ba salt diffusion in literature. For the $0.1 \mathrm{M}$ experiments, Ba diffusivities are less affected, as the density difference is considerably smaller. In terms of transport properties, the advective flux describes the motion of medium itself, rather than its components. Thus, fractionation of $\mathrm{Ba}$ isotopes should not be affected by the advective transport process.

\subsubsection{Ba adsorption onto silica hydrogel}

Another process affecting the transport properties and possibly fractionation of $\mathrm{Ba}$ is adsorption of the species on the surface of the silica gel. Eq. 5 dictates that the diffusive flux decreases with a decreasing concentration gradient, as it would be the case of a simple continuous diffusion process. Neglecting multicomponent diffusion and advective transport, a relative enhancement of the diffusive flux can also be achieved by holding the concentration gradient close to its initial value, e.g. by a virtual removal of dissolved Ba from the fluid 
through adsorption on the surface of the silica gel. As shown by the batch experiment, $\mathrm{Ba}$ is indeed adsorbed onto the gel surface, accompanied by significant isotope fractionation. The question arises to which extent the overall $\mathrm{Ba}$ isotope fractionation measured in the diffusion experiments was affected by adsorption.

Therefore, the diffusive transport model was extended to include an additional fractionation process via adsorption of $\mathrm{Ba}$ on the surface of the silica hydrogel. A fractionation factor of $\alpha=1.00015$ was used, based on the batch experiments of this study. The maximum amount of adsorbed Ba was a fitting parameter and turned out to be variable for the four diffusion experiments (Table 3). In all cases, the fitted value was smaller or equal to the amounts that were experimentally determined by the batch experiments (i.e., $19 \mathrm{mg}$ total $\mathrm{Ba}$ for $0.1 \mathrm{M} \mathrm{BaCl}_{2}$ and $69 \mathrm{mg}$ for $1.0 \mathrm{M} \mathrm{BaCl}_{2}$ starting solution). The model assumes a linear rate $\left(n_{i}^{a d s} * \Delta t\right)$ to define the amount of Ba being adsorbed over time. To the best of the authors' knowledge, no data are available describing the adsorption kinetic of Ba on silica gel, justifying the use of a linear rate law as rough approximation. Moreover, the adsorption kinetics can be used as a fitting parameter as it controls the net flux of $\mathrm{Ba}$, as, for instance, high adsorption rates can significantly decrease the net flux through the gel until saturation of the gel surface is reached, affecting both the concentration profiles in the sink and the predicted isotope fractionation. The presented model runs have been assigned an adsorption rate that reaches saturation of the gel surface with respect to Ba after approximately 100 days, i.e., half of the total run duration. To evaluate whether adsorption kinetics have a significant effect on concentration profiles and resulting fractionation, two end-member scenarios have been modelled (not shown here), one with basically instantaneous adsorption until saturation and another with slow adsorption reaching the experimentally constrained maximum value only at the end of the experiment. Despite the fact that a total of about $10 \%$ of the $\mathrm{Ba}$ is predicted to be adsorbed on the gel surface, it was found that modelling results of both 
scenarios yield concentration profiles and predicated isotope fractionation that are almost indistinguishable.

The extended model predicts a slightly faster decrease in the source's Ba concentration (Fig. 4 a). However, the data fits, especially in the sink (Fig. 4 b), do not improve. In either reservoir, the extended model fails to predict the measured concentration at $t=201$ days. Enabling adsorption requires even higher diffusion coefficients (Table 3, Fig. 6) in order to fit the measured $\mathrm{Ba}$ concentrations in the sink. The maximum amount of adsorbed $\mathrm{Ba}$ calculated by the batch experiments is only a rough estimate, and the adsorption capacity of the silica hydrogel used in the diffusion experiments might deviate. Therefore, we did an additional run with $196 \mathrm{mg}$ maximal adsorbed $\mathrm{Ba}$, corresponding to about $30 \%$ of the total applied $\mathrm{Ba}$ in the 1.0 $\mathrm{M} \mathrm{BaCl}_{2}$ experiments (Fig. 4; grey dashed curves). In this case, the model greatly underestimates the Ba concentration in both the source and the sink after $t=61$ days, while the diffusivities increase even further (Table 3).

The drawback of our extended model is that it does not take in account non-linear adsorption and the evolution of the silica gel surface with time. The silica hydrogel used for this study was formed by the sol-gel process, which is described in detail by Brinker and Scherer (1990). As the gel ages with time, the specific surface area decreases, resulting in fewer surface sinalol groups on which $\mathrm{Ba}^{2+}$ can be adsorbed and eventually inducing desorption if sorption equilibrium is considered. Aging of silica hydrogel becomes more pronounced with increasing $\mathrm{pH}$ and temperature (Brinker and Scherer, 1990). In an earlier study, the specific surface area of a sodium silicate based gel, aged at room temperature under $\mathrm{pH}$ conditions similar to our experiments $(\mathrm{pH} \sim 6$ ), was found to decrease by about 40 to $50 \%$ within the first 10 days after gelation (Sheinfain et al., 1965). Later it was shown that changes in surface area decelerate with time, with $\sim 30 \%$ and $\sim 40 \%$ decrease after 67 and 168 days, respectively (Sheinfain and Neimark, 1973). Based on these studies, changes in silica gel 
surface and adsorption kinetics are likely to have occurred during the course of the diffusion experiments. However, the contribution of adsorption to the overall $\mathrm{Ba}$ isotope fractionation is small, as will be discussed in the following paragraph.

\subsubsection{Ba isotope fractionation factor}

The model fits of the measured $\Delta{ }^{137 / 134} \mathrm{Ba}$ data are quite sensitive to the choice of $\beta$. Based on the fits presented in Fig. 7, we estimate the uncertainty of the modelled $\beta$ to be about \pm 0.002 . Considering diffusion only, $\beta$ takes values for the $0.1 \mathrm{M}$ and $1.0 \mathrm{M}$ experiments of 0.010 and 0.011 , respectively (Table 3 ), which are indistinguishable within uncertainty. There is further no observed dependence on temperature. If adsorption contributed significantly to the overall $\mathrm{Ba}$ isotope fractionation, the model fits of the measured $\Delta^{137 / 134} \mathrm{Ba}$ data would become worse, resulting in a required adjustment of extracted $\beta$ to force the model back to the best fit. This, in turn, would allow us to quantitatively separate the contribution of adsorption and diffusion on the overall measured fractionation. For our experiments, however, differences in the data fits between the models with and without adsorption are minuscule, and even in case of $30 \%$ adsorption of the initially applied $\mathrm{Ba}$, the measured data can still be reasonably well fitted (Fig. $4 \mathrm{f}$ ) with a $\beta$ value of 0.011 for all experiments (Table 3 ). We, therefore, conclude that adsorption contributed only to a small proportion to the overall fractionation, and we can compare the diffusive $\mathrm{Ba}$ isotope fractionation with other aqueous systems.

\section{[insert Fig. 7]}

For Ca, Bourg et al. (2010) experimentally determined a $\beta$ of 0.0045 . The residence time $\tau_{S}$ of water molecules in the first hydration shell of $\mathrm{Ba}$ is shorter than $\tau_{S}$ of $\mathrm{Ca}$ (Hofmann et al., 2013) and due to the inverse correlation of $\beta$ with $\tau_{S}$ (Bourg et al., 2010), we can expect $\beta_{B a} \geq \beta_{C a}$. Further, Watkins et al. (2011) describes a systematic relationship between the 
diffusive isotope fractionation, denoted as $E=2 *\left[\ln \left(D_{2} / D_{1}\right)\right] /\left[\ln \left(m_{1} / m_{2}\right)\right]=2 * \beta$, of cations in water and their solvent-normalised diffusivities (i.e., $D_{\text {cation }} / D_{H 2 O}$ ). We tried to estimate $\beta_{B a}$ by using this relationship. At a given temperature, $D_{H 2 O}$ is constant and $\beta$ correlates directly with the diffusivity. We further assume that $\beta$ is independent from the cation's concentration in diluted solutions. $\beta$ values for $\mathrm{Li}, \mathrm{Na}, \mathrm{K}, \mathrm{Mg}$ and $\mathrm{Ca}$, either experimentally derived (Bourg et al., 2010; Richter et al., 2006) or calculated by MD simulations (Bourg et al., 2010), are plotted against the chloride salt diffusion coefficients at infinite dilution and $75{ }^{\circ} \mathrm{C}$ of the corresponding cations (Fig. 8). A linear relation can be described by $\beta=0.0190 * D-0.0596$ and $\beta=0.0219 * D-0.0681$ for experimental data and MD simulations, respectively. Accordingly, $\beta_{B a}$ values of 0.009 (experimental) and 0.011 (MD simulations) can be calculated. These values are in excellent agreement with our experimentally derived $\beta$ between 0.010 and 0.011 (Table 3).

\section{[insert Fig. 8]}

\subsection{Geological implications}

Following the theory of isotope fractionation (Schauble, 2004), Ba isotope effects under equilibrium conditions should be small, due to low relative mass differences between $\mathrm{Ba}$ isotopes and the fact that $\mathrm{Ba}$ occurs in nature almost exclusively in the +2 oxidation state.

Under kinetically controlled conditions, however, Ba isotope fractionation may be substantial (Hofmann et al., 2013). Indeed, considerable variations in the Ba isotopic composition of natural barites have been found (von Allmen et al., 2010). Marine biogenic barites precipitate in the upper part of the water column in microenvironments that are created by the degradation of planktonic organic matter (see Griffith and Paytan, 2012 for review), and settle to the seafloor. There, the barite crystals can be preserved when buried in oxic sediments as long as sulphate in pore fluids remains saturated with respect to barite (Paytan and Griffith, 
2007). In zones of sulphate reduction in anoxic sediments, however, barite is dissolved and Ba is released into the pore water. The dissolved $\mathrm{Ba}^{2+}$ is then transported upwards by advective fluid flow and/or diffusion into zones with sulphate-bearing pore waters and diagenetic barite precipitates (Torres et al., 1996). Biogenic barite that forms in the water column has $\delta^{137 / 134} \mathrm{Ba}$ values of around $0 \%$ (Böttcher et al., 2012a). Diagenetic barite from the Demerara Rise, on the other hand, was found to be enriched in the light Ba isotopes with a $\delta^{137 / 134} \mathrm{Ba}$ value of around -0.5 \%o (von Allmen et al., 2010). von Allmen et al. (2010) suggested ion diffusion, sorption processes and/or precipitation as possible reasons for the observed differences in $\mathrm{Ba}$ isotopic composition of the barites. Indeed, precipitation enriches barite in the lighter Ba isotopes by about $-0.25 \%$ (von Allmen et al., 2010). The here presented results suggest that, next to precipitation, diffusive transport (with or without accompanying adsorption) may also contribute significantly to the fractionated $\mathrm{Ba}$ isotopic composition of diagenetic barites, as upwardly diffusing $\mathrm{Ba}^{2+}$ in pore waters may become isotopically lighter. The contribution of adsorption on the overall isotope fractionation is likely to be variable for different substrates. Moreover, the direction and magnitude of isotope fractionation during adsorption, in absence of redox changes, is in general controlled by changes in complexation and coordination of the element in solution and at the particle surface (e.g., Jiskra et al., 2012; Juillot et al., 2008; Kafantaris and Borrok, 2014; Mulholland et al., 2015; Siebert et al., 2003; Wasylenki et al., 2011). Therefore, isotope effects caused by adsorption of Ba on organic and mineral particles in marine sediments may differ from here determined fractionation for silica hydrogel under laboratory conditions.

As outlined above, first results indicate that $\mathrm{Ba}$ isotopes are substantially fractionated in marine sediments. The abundance of organic and mineral Ba-bearing particles as well as their Ba isotopic composition might be highly variable, depending on the composition of the sediment and the extent of processes responsible for isotope fractionation, such as $\mathrm{BaSO}_{4}$ 
precipitation after sulphate reduction as well as adsorption and diffusion of $\mathrm{Ba}^{2+}$ ions. Furthermore, it is very likely that a number of other (bio)chemical reactions can cause significant $\mathrm{Ba}$ isotope fractionation as well. Thus, marine sediments might not be isotopically homogenous on a regional to global scale. This, in turn, might prove to be an important aspect of using $\mathrm{Ba}$ isotopes as tracers of subducted sediments, as proposed by Miyazaki et al. (2014) and Nan et al. (2015).

\section{CONCLUSIONS}

Our experiments show that diffusion of dissolved $\mathrm{Ba}^{2+}$ ions through a permeable substrate may result in considerable $\mathrm{Ba}$ isotope fractionation. Despite rather small fractionation factors, measured $\delta{ }^{137 / 134} \mathrm{Ba}$ values exceeded those of former studies by up to one order of magnitude. Diffusive transport and isotope fractionation could be adequately retraced by a numerical transport model. Diffusion of Ba through a silica hydrogel was likely affected by an initial, short-lived advective flux of $\mathrm{BaCl}_{2}$ solution into the silica gel due to density differences of the solutions in the system, multicomponent diffusion in the system $\mathrm{BaCl}_{2}-\mathrm{NaCl}-\mathrm{H}_{2} \mathrm{O}$ and adsorption of $\mathrm{Ba}$ onto the gel surface. Multicomponent diffusion and gravitational mixing have presumably negligible effects on diffusive isotope fractionation studied here. In other (natural) systems, however, multicomponent diffusion and advection are likely to influence other parameters such as $\mathrm{pH}$ and adsorption capacities, and it is therefore desirable to incorporate these effects in future models.

Isotope fractionation during the diffusion experiments is related to subtle mass-dependent differences in the effective diffusivities of the isotopes $\left(D \propto m^{-\beta}\right)$, with $\beta$ factors between 0.010 and 0.011 for Ba diffusion. Adsorption of Ba onto the silica hydrogel surface was accompanied by isotope fractionation with $\alpha=1.00015 \pm 0.00008$, determined by batch 
experiments. The contribution of adsorption to the overall $\mathrm{Ba}$ isotope fractionation in our diffusion experiments was evaluated by extending the numerical transport model by a linear adsorption term. Adsorption was subsequently found to have a small impact on the observed Ba isotope fractionation. As diffusion is a pervasive process in nature, the results of our study indicate that considerable transport-driven Ba isotope fractionation can be expected, especially in a highly permeable and surface-reactive substrate such as marine sediments.

\section{Acknowledgements}

We thank Maria Hierz and Andrea Wolf from the TU Graz for laboratory support with preparation of silica hydrogel and conduction of the diffusion experiments. Jennifer Druhan and two anonymous reviewers are thanked for constructive comments that greatly improved the quality of the manuscript. This work was supported by the Swiss National Science Foundation (SNSF Grant 200021_140223 to TFN). The paper is a contribution to the collaborative research initiative CHARON, financed by the German Research Foundation.

\section{Appendix A. Supplementary data}

Supplementary data to this article can be found online at $\mathrm{xxx}$

\section{References}

Bishop, J. K. B., (1988) The barite-opal-organic carbon association in oceanic particulate matter. Nature 332, 341-343.

Bolou-Bi, E. B., Poszwa, A., Leyval, C.and Vigier, N., (2010) Experimental determination of magnesium isotope fractionation during higher plant growth. Geochim. Cosmochim. Acta 74, 2523-2537.

Bolt, G. H., (1957) Determination of the charge density of silica sols. J. Phys. Chem. A 61, 1166-1169.

Böttcher, M., van Allmen, K., Paytan, A., Neubert, N., Brumsack, H. J., Samankassou, E.and Nägler, T. F., (2012a) A new look on the barium cycle: Stable barium isotope fractionation in ODP sediments and calibration experiments. Mineral. Mag. 76, 1495.

Böttcher, M. E., Geprägs, P., Neubert, N., Von Allmen, K., Pretet, C., Samankassou, E.and Nägler, T. F., (2012b) Barium isotope fractionation during experimental formation of 
the double carbonate $\mathrm{BaMn}\left[\mathrm{CO}_{3}\right]_{2}$ at ambient temperature. Isot. Environ. Healt. S. $\mathbf{4 8}$, 457-463.

Bourg, I. C., Richter, F. M., Christensen, J. N.and Sposito, G., (2010) Isotopic mass dependence of metal cation diffusion coefficients in liquid water. Geochim. Cosmochim. Acta 74, 2249-2256.

Bourg, I. C.and Sposito, G., (2007) Molecular dynamics simulations of kinetic isotope fractionation during the diffusion of ionic species in liquid water. Geochim. Cosmochim. Acta 71, 5583-5589.

Bourg, I. C.and Sposito, G., (2008) Isotopic fractionation of noble gases by diffusion in liquid water: Molecular dynamics simulations and hydrologic applications. Geochim. Cosmochim. Acta 72, 2237-2247.

Brinker, C. J.and Scherer, G. W., 1990. Sol-Gel Science: The Physics and Chemistry of SolGel Processing. Academic Press, Boston.

Bullen, T. D. and Chadwick, O. A., (2016) Ca, Sr and Ba stable isotopes reveal the fate of soil nutrients along a tropical climosequence in Hawaii. Chem. Geol. 422, 25-45.

Cao, Z., Siebert, C., Hathorne, E. C., Dai, M.and Frank, M., (2016) Constraining the oceanic barium cycle with stable barium isotopes. Earth Planet. Sc. Lett. 434, 1-9.

Chopra, R., Richter, F. M., Watson, E. B.and Scullard, C. R., (2012) Magnesium isotope fractionation by chemical diffusion in natural settings and in laboratory analogues. Geochim. Cosmochim. Acta 88, 1-18.

Compston, W.and Oversby, V. M., (1969) Lead Isotopic Analysis Using a Double Spike. J. Geophys. Res. 74, 4338-4348.

Cronan, D. S.and Hodkinson, R. A., (1997) Geochemistry of hydrothermal sediments from ODP sites 834 and 835 in the Lau Basin, southwest Pacific. Mar. Geol. 141, 237-268.

de Laeter, J. R., Böhlke, J. K., De Bièvre, P., Hidaka, H., Peiser, H. S., Rosman, K. J. R.and Taylor, P. D. P., (2003) Atomic weights of the elements: Review 2000 (IUPAC Technical report). Puer Appl. Chem. 75, 683-800.

Debacq, M., Hulin, J.-P., Salin, D., Perrin, B.and Hinch, E. J., (2003) Buoyant mixing of miscible fluids of varying viscosities in vertical tubes. Phys. Fluids 15, 3846-3855.

Dehairs, F., Chesselet, R.and Jedwab, J., (1980) Discrete suspended particles of barite and the barium cycle in the open ocean. Earth Planet. Sc. Lett. 49, 528-550.

Dymond, J.and Collier, R., (1996) Particulate barium fluxes and their relationships to biological productivity. Deep-Sea Res. Pt. II 43, 1283-1308.

Dymond, J., Suess, E.and Lyle, M., (1992) Barium in deep-sea sediment: A geochemical proxy for paleoproductivity. Paleoceanography 7, 163-181.

Elliott, T., Plank, T., Zindler, A., White, W.and Bourdon, B., (1997) Element transport from slab to volcanic front at the Mariana arc. J. Geophys. Res. 102, 14991-15019.

François, R., Honjo, S., Manganini, S. J.and Ravizza, G. E., (1995) Biogenic barium fluxes to the deep sea: Implications for paleoproductivity reconstruction. Global Biogeochem. Cy. 9, 289-303.

Ganeshram, R. S., François, R., Commeau, J.and Brown-Leger, S. L., (2003) An experimental investigation of barite formation in seawater. Geochim. Cosmochim. Acta 67, 25992605.

Goldberg, E. D.and Arrhenius, G. O. S., (1958) Chemistry of Pacific pelagic sediments. Geochim. Cosmochim. Acta 13, 153-198.

Griffith, E. M.and Paytan, A., (2012) Barite in the ocean - occurrence, geochemistry and palaeoceanographic applications. Sedimentology 59, 1817-1835.

Gussone, N., Eisenhauer, A., Heuser, A., Dietzel, M., Bock, B., Böhm, F., Spero, H., Lea, D. W., Bijma, J.and Nägler, T. F., (2003) Model for kinetic effects on calcium isotope fractionation $\left(\delta^{44} \mathrm{Ca}\right)$ in inorganic aragonite and cultured planktonic foraminifera. Geochim. Cosmochim. Acta 67, 1375-1382.

Hindshaw, R. S., Reynolds, B. C., Wiederhold, J. G., Kiczka, M., Kretzschmar, R.and Bourdon, B., (2013) Calcium isotope fractionation in alpine plants. Biogeochemistry 112, 373-388.

Hofmann, A. E., Bourg, I. C.and DePaolo, D. J., (2013) Ion desolvation as a mechanism for kinetic isotope fractionation in aqueous systems. PNAS 109, 18689-18694. 
Horner, T. J., Kinsley, C. W.and Nielsen, S. G., (2015) Barium-isotopic fractionation in seawater mediated by barite cycling and oceanic circulation. Earth Planet. Sc. Lett. 430, 511-522.

Hsieh, Y.-T.and Henderson, G. M., (2015) Barium stable isotope fractionation in seawater. Goldschmidt Abstracts, 1326.

Huang, K.-J., Teng, F.-Z., Wei, G.-J., Ma, J.-L.and Bao, Z.-Y., (2012) Adsorption- and desorption-controlled magnesium isotope fractionation during extreme weathering of basalt in Hainan Island,China. Earth Planet. Sc. Lett. 359-360, 73-83.

Hull, P. M.and Norris, R. D., (2011) Diverse patterns of ocean export productivity change across the Cretaceous-Paleogene boundary: New insights from biogenic barium. Paleoceanography 26, PA3205.

Jiskra, M., Wiederhold, J. G., Bourdon, B.and Kretzschmar, R., (2012) Solution Speciation Controls Mercury Isotope Fractionation of $\mathrm{Hg}(\mathrm{II})$ Sorption to Goethite. Environ. Sci. Technol. 46, 6654-6662.

Juillot, F., Maréchal, C., Ponthieu, M., Cacaly, S., Morin, G., Benedetti, M., Hazemann, J. L., Proux, O.and Guyot, F., (2008) Zn isotopic fractionation caused by sorption on goethite and 2-Lines ferrihydrite. Geochim. Cosmochim. Acta 72, 4886-4900.

Kafantaris, F.-C. A.and Borrok, D. M., (2014) Zinc isotope fractionation during surface adsorption and intracellular incorporation by bacteria. Chem. Geol. 366, 42-51.

Kinsley, C. W., Horner, T. J., Nielsen, S. G.and Lam, P. J., (2015) Barium-isotopic cycling in Southern Ocean particulate matter. Goldschmidt Abstracts, 1596.

Kuritani, T., Ohtani, E.and Kimura, J.-I., (2011) Intensive hydration of the mantle transition zone beneath China caused by ancient slab stagnation. Nat. Geosci. 4, 713-716.

Leaist, D. G.and Curtis, N., (1999) Hartley-Crank equations for coupled diffusion in concentrated mixed electrolyte solutions. The $\mathrm{CaCl}_{2}+\mathrm{HCl}+\mathrm{H}_{2} \mathrm{O}$ system. J. Solution Chem. 28, 341-366.

Li, Y.-H.and Gregory, S., (1974) Diffusion of ions in sea water and in deep-sea sediments. Geochim. Cosmochim. Acta 88, 708-714.

McManus, J., Berelson, W. M., Klinkhammer, G. P., Johnson, K. S., Coale, K. H., Anderson, R. F., Kumar, N., Burdige, D. J., Hammond, D. E., Brumsack, H. J., McCorkle, D. C.and Rushdi, A., (1998) Geochemistry of barium in marine sediments: Implications for its use as a paleoproxy. Geochim. Cosmochim. Acta 62, 3453-3473.

Miyazaki, T., Kimura, J.-I.and Chang, Q., (2014) Analysis of stable isotope ratios of Ba by double-spike standard-bracketing using multiple-collector inductively coupled plasma mass spectrometry. J. Anal. Atom. Spectrom. 29, 483-490.

Morris, J. D.and Ryan, J. G., (2003) Subduction zone processes and implications for changing composition of the upper and lower mantle. In: Subduction zone processes and implications for changing composition of the upper and lower mantle, Book, pp. 451470.

Moynier, F., Pringle, E. A., Bouvier, A.and Moureau, J., (2015) Barium stable isotope composition of the Earth, meteorites, and calcium-aluminum-rich inclusions. Chem. Geol. 413, 1-6.

Mulholland, D. S., Poitrasson, F., Shirokova, L. S., González, A. G., Pokrovsky, O. S., Boaventura, G. R.and Vieira, L. C., (2015) Iron isotope fractionation during Fe(II) and $\mathrm{Fe}(\mathrm{III})$ adsorption on cyanobacteria. Chem. Geol. 400, 24-33.

Nan, X., Wu, F., Zhang, Z., Hou, Z., Huang, F.and Yu, H., (2015) High-precision barium isotope measurement by MC-ICP-MS. J. Anal. Atom. Spectrom. 30, 2307-2315.

Parkhurst, D. L.and Appelo, C. A. J., (2013) Description of input and examples for PHREEQC version 3: a computer program for speciation, batch-reaction, onedimensional transport, and inverse geochemical calculations. In: Description of input and examples for PHREEQC version 3: a computer program for speciation, batchreaction, one-dimensional transport, and inverse geochemical calculations, Book. U.S. Geological Survey, Reston, VA, p. A43.

Paytan, A., Averyt, K., Faul, K., Gray, E.and Thomas, E., (2007) Barite accumulation, ocean productivity, and $\mathrm{Sr} / \mathrm{Ba}$ in barite across the Paleocene-Eocene Thermal Maximum. Geology 35, 1139-1142.

Paytan, A.and Griffith, E. M., (2007) Marine barite: Recorder of variations in ocean export productivity. Deep-Sea Res. Pt. II 54, 687-705. 
Paytan, A.and Kastner, M., (1996) Benthic Ba fluxes in the central Equatorial Pacific, implications for the oceanic Ba cycle. Earth Planet. Sc. Lett. 142, 439-450.

Pearce, J. A.and Stern, R. J., (2006) Origin of back-arc basin magmas: Trace element and isotope perspectives. In: Origin of back-arc basin magmas: Trace element and isotope perspectives, Christie, D.M., Fisher, C.R., Sang-Mook, L.and Givens, S. (eds.), Book. American Geophysical Union, Washington DC, pp. 63-86.

Plank, T.and Langmuir, C. H., (1993) Tracing trace elements from sediment input to volcanic output at subduction zones. Nature 362, 739-743.

Plank, T.and Langmuir, C. H., (1998) The chemical composition of subducting sediment and its consequences for the crust and mantle. Chem. Geol. 145, 325-394.

Pretet, C., van Zuilen, K., Nägler, T. F., Reynaud, S., Böttcher, M. E.and Samankassou, E., (2016) Constraints on barium isotope fractionation during aragonite precipitation by corals. The Depositional Record 1, 118-129.

Puchalska, D.and Atkinson, G., (1991) Densities and apparent molal volumes of aqueous $\mathrm{BaCI}_{2}$ solutions from 15 to $140{ }^{\circ} \mathrm{C}$ and from 1 to 200 bar. J. Chem. Eng. Data 36, 449452.

Rapp, R. P., Irifune, T., Shimizu, N., Nishiyama, N., Norman, M. D.and Inoue, T., (2008) Subduction recycling of continental sediments and the origin of geochemically enriched reservoirs in the deep mantle. Earth Planet. Sc. Lett. 271, 14-23.

Richter, F. M., Davis, A. M., DePaolo, D. J.and Watson, E. B., (2003) Isotope fractionation by chemical diffusion between molten basalt and rhyolite. Geochim. Cosmochim. Acta 67, 3905-3923.

Richter, F. M., Liang, Y.and Davis, A. M., (1999) Isotope fractionation by diffusion in molten oxides. Geochim. Cosmochim. Acta 63, 2853-2861.

Richter, F. M., Mendybaev, R. A., Christensen, J. N., Hutcheon, I. D., Williams, R. W., Sturchio, N. C.and Beloso Jr., A. D., (2006) Kinetic isotopic fractionation during diffusion of ionic species in water. Geochim. Cosmochim. Acta 70, 277-289.

Richter, F. M., Watson, E. B., Mendybaev, R. A., Dauphas, N., Georg, B., Watkins, J.and Valley, J., (2009) Isotopic fractionation of the major elements of molten basalt by chemical and thermal diffusion. Geochim. Cosmochim. Acta 73, 4250-4263.

Richter, F. M., Watson, E. B., Mendybaev, R. A., Teng, F.-Z.and Janney, P. E., (2008) Magnesium isotope fractionation in silicate melts by chemical and thermal diffusion. Geochim. Cosmochim. Acta 72, 206-220.

Robinson, R. A.and Stokes, R. H., 2002. Electrolyte solutions. Dover Publications, Mineola, NY.

Rustad, J. R., Casey, W. H., Yin, Q.-Z., Bylaska, E. J., Felmy, A. R., Bogatko, S. A., Jackson, V. E.and Dixon, D. A., (2010) Isotopic fractionation of $\mathrm{Mg}^{2+}(\mathrm{aq}), \mathrm{Ca}^{2+}(\mathrm{aq})$, and $\mathrm{Fe}^{2+}(\mathrm{aq})$ with carbonate minerals. Geochim. Cosmochim. Acta 74, 6301-6323.

Schauble, E. A., (2004) Applying Stable Isotope Fractionation Theory to New Systems. In: Applying Stable Isotope Fractionation Theory to New Systems, Johnson, C.M., Beard, B.L.and Albarède, F. (eds.), Book. Mineralogical Society of America, Washington, pp. 65-111.

Sheinfain, R. Y.and Neimark, I. E., (1973) Role of the ageing of silicic acid hydrogel in the formation of the porous structure of silica gel. In: Role of the ageing of silicic acid hydrogel in the formation of the porous structure of silica gel, Strazhesko, D.N. (ed.), Book. John Wiley \& Sons, New York, pp. 87-95.

Sheinfain, R. Y., Stas, O. P.and Neimark, I. E., (1965) Mechanism of porous structure formation of silica gels. IV. Regulation of silica structure by combination of variation of gel aging time and the nature of intermicellar liquid. Colloid J. USSR 27, 781-784.

Siebert, C., Nägler, T. F., von Blanckenburg, F.and Kramers, J. D., (2003) Molybdenum isotope records as a potential new proxy for paleoceanography. Earth Planet. Sc. Lett. 211, 159-171.

Steefel, C. I.and Maher, K., (2009) Fluid-rock interaction: a reactive transport approach. In: Fluid-rock interaction: a reactive transport approach, Oelkers, E.H.and Schott, J. (eds.), Book. Mineralogical Society of America, Washington, pp. 485-532.

Torres, M. E., Brumsack, H. J., Bohrmann, G.and Emeis, K. C., (1996) Barite fronts in continental margin sediments: A new look at barium remobilization in the zone of sulfate reduction and formation of heavy barites in diagenetic fronts. Chem. Geol. 127. 
von Allmen, K., Böttcher, M. E., Samankassou, E.and Nägler, T. F., (2010) Barium isotope fractionation in the global barium cycle: First evidence from barium minerals and precipitation experiments. Chem. Geol. 277, 70-77.

Wasylenki, L. E., Weeks, C. L., Bargar, J. R., Spiro, T. G., Hein, J. R.and Anbar, A. D., (2011) The molecular mechanism of Mo isotope fractionation during adsorption to birnessite. Geochim. Cosmochim. Acta 75, 5019-5031.

Watkins, J. M., DePaolo, D. J., Huber, C.and Ryerson, F. J., (2009) Liquid compositiondependence of calcium isotope fractionation during diffusion in molten silicates. Geochim. Cosmochim. Acta 73, 7341-7359.

Watkins, J. M., DePaolo, D. J., Ryerson, F. J.and Peterson, B. T., (2011) Influence of liquid structure on diffusive isotope separation in molten silicates and aqueous solutions. Geochim. Cosmochim. Acta 75, 3103-3118. 


\section{Tables}

Table 1

Ba concentration and isotope data of diffusion experiments

\begin{tabular}{|c|c|c|c|c|c|c|c|c|}
\hline \multirow{2}{*}{ sample ID } & \multirow{2}{*}{$\begin{array}{c}\text { time } \\
\text { (days) }\end{array}$} & \multirow{2}{*}{$\begin{array}{c}\mathrm{Ba} \\
(\mu \mathrm{g} / \mathrm{g})\end{array}$} & \multirow{2}{*}{$2 \mathrm{sd}$} & \multicolumn{4}{|c|}{$\delta^{137 / 134} \mathrm{Ba}$} & \multirow{2}{*}{$\Delta^{137 / 134} \mathrm{Ba}^{\mathrm{a}}$} \\
\hline & & & & repl 1 & repl 2 & average & $2 \mathrm{sd}$ & \\
\hline \multicolumn{9}{|l|}{ Initial solutions } \\
\hline G_0.1M_BaCl2 & 0 & 13314 & 246 & 0.07 & 0.05 & 0.06 & 0.03 & $\mathrm{n} / \mathrm{a}$ \\
\hline G2_0.1M_BaCl2 & 0 & 13046 & 285 & 0.06 & 0.08 & 0.07 & 0.04 & $\mathrm{n} / \mathrm{a}$ \\
\hline G_1.0M_BaCl2 & 0 & 132740 & 2814 & 0.17 & 0.12 & 0.15 & 0.07 & $\mathrm{n} / \mathrm{a}$ \\
\hline G2_1.0M_BaCl2 & 0 & 129792 & 2929 & 0.01 & 0.01 & 0.01 & 0.00 & $\mathrm{n} / \mathrm{a}$ \\
\hline
\end{tabular}

Sink

G_0.1_10_2d_H2O

$\begin{array}{llll}2 & 0.005 & 0.005 & n / d\end{array}$

G_0.1_10_6d_H2O

$\begin{array}{lll}6 & 0.007 & 0.001\end{array}$

G_0.1_10_12d_H2O

12

$0.479 \quad 0.004$

$-0.95$

$-0.93$

$n / d$

G_0.1_10_20d_H2O

5.1

$0.07 \quad-1.01 \quad-1.01$

$-0.94$

0.02

$-1.00$

G_0.1_10_27d_H2O

24.3

$-1.01$

0.01

$-1.07$

G2_0.1_10_20d_H2O

27

0.3

$-0.79$

0.02

$-0.85$

G2_0.1_10_40d_H2O

6.16

0.08

$-0.95$

$-1.02$

G2_0.1_10_61d_H2O

40

83

$-0.84$

0.02

$-0.91$

G2_0.1_10_79d_H2O

260

$-0.54$

0.04

$-0.61$

G2_0.1_10_201d_H2O

$-0.39$

$-0.46$

201

2104

$10 \quad-0.40$

0.04

$-0.20$

G_0.1_25_2d_H20

G_0.1_25_6d_H2O

G_0.1_25_12d_H2O

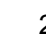

0.010

$\begin{array}{lll}44 & -0.15 & -0.11\end{array}$

$-0.13$

0.06

/a

a

G_0.1_25_20d_H2O

0.198

0.003

$\mathrm{n} / \mathrm{d}$
$-\quad-1.61$

G_0.1_25_27d_H2O

4.0

0.002

$-1.61$

$-1.61$

0.09

$-1.67$

37.0

$0.1-1.10$

$-1.10$

$-1.10$

0.00

$-1.16$

20

125

$-0.81$

$-0.74$

0.20

$-0.80$

G2_0.1_25_20d_H2O

25.7

$-0.57$

0.24

$-0.63$

G2_0.1_25_40d_H2O

20

40

G2_0.1_25_61d_H2O

270

$-0.88$

0.04

$-0.95$

G2_0.1_25_79d_H2O

750

$-0.57$

0.02

$-0.64$

61

1070

$-0.43$

0.03

$-0.50$

G2_0.1_25_201d_H2O

2794

$20 \quad-0.28$

$-0.44$

$-0.30$

0.07

$-0.37$

201

G_1.0_10_2d_H2O

G_1.0_10_6d_H2O

G_1.0_10_12d_H2O

G_1.0_10_20d_H2O

$\begin{array}{ll}66 & -0.01\end{array}$

$-0.03$

$-0.02$

0.03

$-0.09$

G_1.0_10_27d_H2O

0.006

0.002

n/d

6

12

0.034

0.001

$-15$

8.9

0.1

$-2.15$

$\begin{array}{lll}0.09 & b & -2.30\end{array}$

154

-1.55
-0.96

0.08

$-1.70$

20

783

$-0.96$

0.04

$-1.10$

G2_1.0_10_20d_H2O

186

$-0.63$

0.04

$-0.78$

G2_1.0_10_40d_H2O

2091

$-0.93$

0.05

$-0.95$

G2_1.0_10_61d_H2O

61

G2_1.0_10_79d_H2O

5415

$-0.71$

0.06

$-0.72$

G2_1.0_10_201d_H2O

8700

$-0.47$

0.06

$-0.48$

79

152

$-0.38$

0.07

$-0.39$

201

25195

60

$-0.07$

0.07

$-0.08$

G_1.0_25_2d_H2O

$\begin{array}{lll}2 & 0.008 & 0.001\end{array}$

$\mathrm{n} / \mathrm{d}$

G_1.0_25_6d_H2O

6

1.12

0.03

$-2.06 \quad-1.99$

$-2.02$

0.10

$-2.17$ 


$\begin{array}{lrrrrrrrr}\text { G_1.0_25_12d_H2O } & 12 & 113 & 2 & -1.02 & -1.11 & -1.07 & 0.13 & -1.21 \\ \text { G_1.0_25_20d_H2O } & 20 & 904 & 16 & -0.79 & -0.91 & -0.85 & 0.16 & -1.00 \\ \text { G_1.0_25_27d_H2O } & 27 & 2377 & 43 & -0.55 & -0.58 & -0.57 & 0.05 & -0.72 \\ \text { G2_1.0_25_20d_H2O } & 20 & 605 & 11 & -0.84 & -0.79 & -0.81 & 0.08 & -0.83 \\ \text { G2_1.0_25_40d_H2O } & 40 & 4580 & 127 & -0.67 & -0.64 & -0.65 & 0.04 & -0.67 \\ \text { G2_1.0_25_61d_H2O } & 61 & 10394 & 204 & -0.32 & -0.32 & -0.32 & 0.00 & -0.33 \\ \text { G2_1.0_25_79d_H2O } & 79 & 14613 & 302 & -0.25 & -0.26 & -0.25 & 0.01 & -0.27 \\ \text { G2_1.0_25_201d_H2O } & 201 & 33860 & 877 & -0.06 & -0.03 & -0.05 & 0.05 & -0.06\end{array}$

\section{Source}

G_0.1_10_2d_BaCl2

G_0.1_10_6d_BaCl2

G_0.1_10_12d_BaCl2

G_0.1_10_20d_BaCl2

G_0.1_10_27d_BaCl2

G2_0.1_10_20d_BaCl2

G2_0.1_10_40d_BaCl2

G2_0.1_10_61d_BaCl2

G2_0.1_10_79d_BaCl2

G2_0.1_10_201d_BaCl2

G_0.1_25_2d_H20

G_0.1_25_6d_BaCl2

G_0.1_25_12d_BaCl2

G_0.1_25_20d_BaCl2

G_0.1_25_27d_BaCl2

G2_0.1_25_20d_BaCl2

G2_0.1_25_40d_BaCl2

G2_0.1_25_61d_BaCl2

G2_0.1_25_79d_BaCl2

G2_0.1_25_201d_BaCl2

2
6

12

20

27

20

40

61

79

201

G_1.0_10_2d_BaCl2

G_1.0_10_6d_BaCl2

G_1.0_10_12d_BaCl2

G_1.0_10_20d_BaCl2

G_1.0_10_27d_BaCl2

G2_1.0_10_20d_BaCl2

G2_1.0_10_40d_BaCl2

G2_1.0_10_61d_BaCl2

G2_1.0_10_79d_BaCl2

G2_1.0_10_201d_BaCl2

11864
10988
10223
9405
8450
9392
7492
6936
6307
4589

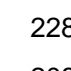

208

191

176

156

184

144

133

121

87

0.09

0.17

0.13

0.12

0.11

0.11

0.10

0.07

0.10

0.08

0.08
0.09

0.23

0.15

0.09

0.09

0.12

0.05

0.05

0.30

217

196

0.10

0.12

0.08

0.12

0.10

168

0.13

0.10

0.20

0.21

129

0.10

0.12

0.08

0.07

0.02

0.10

0.13

0.14

4066

114

0.13

92

0.13

.

2397

1913

0.10

0.08

0.14

0.19

1720

0.09

0.19

1589

0.01

0.25

71370

1496

0.12

0.13

0.07

1562

1383

0.06

0.12

0.06

$0.13 \quad 0.09$

1230

0.04

0.11

1401

0.16

0.19

56592

101318

2165

1782

0.13

0.17

0.12

0.19

0.09

1653
1504

0.14

0.16

1400

0.10

0.17

1497

$\begin{array}{lll}0.13 & 0.11 & 0.07 \\ 0.10 & 0.09 & 0.04 \\ 0.11 & 0.01 & 0.06 \\ 0.13 & 0.07 & 0.07 \\ 0.10 & 0.02 & 0.04 \\ 0.08 & 0.04 & 0.01 \\ 0.11 & 0.03 & 0.04 \\ 0.06 & 0.04 & 0.00 \\ 0.07 & 0.06 & 0.00 \\ 0.27 & 0.10 & 0.20\end{array}$

$0.09 \quad 0.03$

$0.12 \quad 0.00$

$0.12 \quad 0.05$

$0.15 \quad 0.14$

$0.15 \quad 0.16$

$0.10 \quad 0.07$

$0.05 \quad 0.08$

$0.10 \quad 0.00$

$0.13 \quad 0.01$

$0.13 \quad 0.01$

$\begin{array}{ll}0.09 \quad 0.03 \\ 0.13 & 0.04\end{array}$

$0.13 \quad 0.04$

$0.14 \quad 0.14$

$\begin{array}{ll}0.13 & 0.35\end{array}$

$0.13 \quad 0.02$

$0.07 \quad 0.01$

$0.09 \quad 0.09$

0.11

0.08

0.18

0.06

0.09

0.04

0.03

0.06

0.06

0.09

0.10

0.03

$-0.01$

0.03

0.06

0.06

$-0.06$

$-0.02$

$-0.01$

$-0.02$

$-0.02$

0.05

0.08

0.10

0.06

0.16

0.00

0.01

$-0.03$

0.00

$-0.01$

0.06 


\begin{tabular}{lrlllllll} 
G2_1.0_25_40d_BaCl2 & 40 & 60062 & 1306 & 0.12 & 0.07 & 0.10 & 0.07 & 0.09 \\
G2_1.0_25_61d_BaCl2 & 61 & 53541 & 1163 & 0.17 & 0.11 & 0.14 & 0.08 & 0.12 \\
G2_1.0_25_79d_BaCl2 & 79 & 48871 & 1255 & 0.09 & 0.24 & 0.16 & 0.21 & 0.15 \\
G2_1.0_25_201d_BaCl2 & 201 & 41404 & 1333 & 0.16 & 0.13 & 0.14 & 0.05 & 0.13 \\
\hline
\end{tabular}

${ }^{a}$ isotopic composition relative to the starting solution

${ }^{\mathrm{b}}$ intermediate measurement precision $2 \mathrm{~s}_{\mathrm{p}}$ (see main text)

Table 2

$\mathrm{Ba}$ isotope data of batch equilibrium experiment

\begin{tabular}{|c|c|c|c|c|c|c|c|c|c|c|}
\hline \multirow{2}{*}{ sample ID } & \multirow{2}{*}{$\begin{array}{l}\text { gel } \\
\text { (g) }\end{array}$} & \multirow{2}{*}{$\begin{array}{l}\text { gel } \\
(\mathrm{ml})\end{array}$} & \multirow{2}{*}{$\begin{array}{c}\mathrm{Ba} \\
(\mu \mathrm{g} / \mathrm{g})\end{array}$} & \multirow{2}{*}{$2 \mathrm{sd}$} & \multicolumn{4}{|c|}{$\delta^{137 / 134} \mathrm{Ba}$} & & \multirow{2}{*}{$\Delta^{137 / 134} \mathrm{Ba}^{a}$} \\
\hline & & & & & repl 1 & repl 2 & average & $2 \mathrm{sd}$ & & \\
\hline \multicolumn{11}{|l|}{$0.1 \mathrm{M} \mathrm{BaCl}_{2}$} \\
\hline ads_diss & & & 12188 & 498 & 0.11 & 0.07 & 0.09 & 0.05 & & $\mathrm{n} / \mathrm{a}$ \\
\hline ads_wash-I & & & 767 & 17 & 0.05 & - & 0.05 & 0.09 & $\mathrm{~b}$ & -0.03 \\
\hline ads_wash-II & & & 187 & 4 & 0.08 & - & 0.08 & 0.09 & $\mathrm{~b}$ & -0.01 \\
\hline ads_gel & 0.0473 & 0.0436 & 91 & 1 & 0.22 & 0.20 & 0.21 & 0.03 & & 0.12 \\
\hline \multicolumn{11}{|l|}{$1.0 \mathrm{M} \mathrm{BaCl}_{2}$} \\
\hline ads_diss & & & 125229 & 5208 & 0.05 & 0.05 & 0.05 & 0.00 & & $\mathrm{n} / \mathrm{a}$ \\
\hline ads_wash-I & & & 5925 & 141 & 0.05 & - & 0.05 & 0.09 & b & 0.00 \\
\hline ads_wash-II & & & 1247 & 54 & 0.08 & - & 0.08 & 0.09 & b & 0.03 \\
\hline ads_gel & 0.0572 & 0.0528 & 404 & 15 & 0.23 & 0.22 & 0.23 & 0.02 & & 0.17 \\
\hline
\end{tabular}

a isotopic composition relative to 'ads_diss'

${ }^{\mathrm{b}}$ intermediate measurement precision $2 \mathrm{~s}_{\mathrm{p}}$ (see main text)

Table 3

Parameters extracted from the diffusive transport model (with $u=0.95$ )

\begin{tabular}{ccccccc}
\hline \multirow{2}{*}{ experiment } & \multicolumn{2}{c}{ diffusion only } & \multicolumn{3}{c}{ with adsorption } & salt diffusion $^{\text {a }}$ \\
\cline { 2 - 7 } & $\begin{array}{c}D^{\text {eff }}\left(10^{-5} \mathrm{~cm}^{2} \mathrm{~s}^{-}\right. \\
\text {( }\end{array}$ & $\beta$ & $D^{\text {eff }}\left(10^{-5} \mathrm{~cm}^{2} \mathrm{~s}^{-1}\right)$ & $\beta$ & $\begin{array}{c}\text { Ba adsorbed } \\
(\mathrm{mg})\end{array}$ & $D\left(10^{-5} \mathrm{~cm}^{2} \mathrm{~s}^{-1}\right)$ \\
\hline $0.1 \mathrm{M} / 10^{\circ} \mathrm{C}$ & 0.73 & 0.010 & 0.80 & 0.011 & 3.2 & 0.75 \\
$0.1 \mathrm{M} / 25^{\circ} \mathrm{C}$ & 1.10 & 0.010 & 1.20 & 0.011 & 3.2 & 1.16 \\
$1.0 \mathrm{M} / 10^{\circ} \mathrm{C}$ & 0.98 & 0.011 & 1.10 & 0.011 & 68.5 & 0.76 \\
& & & $1.40^{\mathrm{b}}$ & $0.011^{\mathrm{b}}$ & $196.0^{\mathrm{b}}$ & \\
$1.0 \mathrm{M} / 25^{\circ} \mathrm{C}$ & 1.40 & 0.011 & 1.50 & 0.011 & 12.2 & 1.18 \\
\hline
\end{tabular}

${ }^{\text {a }}$ salt diffusion coefficients for 0.1 and $1.0 \mathrm{M}$ at $25^{\circ} \mathrm{C}$ were taken from Robinson and Stokes (2002); diffusion coefficients at $10^{\circ} \mathrm{C}$ were calculated using the Stokes-Einstein equation

${ }^{\mathrm{b}}$ model run with $30 \%$ adsorption 


\section{Figure captions}

Fig. 1. (a) Experimental setup of diffusion experiments. The bottom of the glass tube was filled with silica hydrogel. Source and sink reservoirs were filled with $\mathrm{BaCl}_{2}$ solution and deionized water, respectively. (b) The solidified gel consisted of a silica network with a porosity of about 0.98 . The pores were initially filled with a $\sim 0.8 \mathrm{M} \mathrm{NaCl}$ solution as the result of the sol-gel process.

Fig. 2. Concentration data (blue) and Ba isotopic composition (black) of all four diffusion experiments plotted against time. Development of the source and sink is shown on the left (a, $\mathrm{c}, \mathrm{e}, \mathrm{f})$ and on the right hand side $(\mathrm{b}, \mathrm{d}, \mathrm{f}, \mathrm{h})$, respectively. The experiments were conducted in two separate series ( $\mathrm{G}$ and $\mathrm{G} 2$ ), with an overlap at $\mathrm{t}=20$ days. Data points are connected by straight lines for clarity only. Individual analytical uncertainties $(2 \mathrm{sd})$, based on 2 repeated measurements, are indicated by the error bars, which may be smaller than symbol size. $\Delta^{137 / 134} \mathrm{Ba}$ of the initial $\mathrm{BaCl}_{2}$ solution is $0 \%$ by default, 2 sd uncertainty is shown by grey bar.

Fig. 3. Diffusive transport model. See text for details. (a) Spatial distribution of ${ }^{134} \mathrm{Ba}$ (grey) and ${ }^{137} \mathrm{Ba}$ (black) (given in $10^{-5} \mathrm{~mol}$ per $\mathrm{mm}$ ) at the beginning (solid lines) and end (dashed lines) of the experiment. At $t=0$ days, the source has a homogenous Ba concentration, gel and sink reservoirs do not contain Ba. Diffusion and isotope fractionation were exemplarily modelled for the $1.0 \mathrm{M} / 10{ }^{\circ} \mathrm{C}$ experiment with an effective diffusion coefficient $D^{\text {eff }}$ of $0.98^{*} 10^{-5} \mathrm{~cm}^{2} \mathrm{~s}^{-1}$ for ${ }^{137} \mathrm{Ba}$ and a $\beta$ value of 0.011 . (b) Ba isotopic composition relative to the initial $\mathrm{BaCl}_{2}$ solution. The sink reservoir becomes enriched in ${ }^{134} \mathrm{Ba}$ as the result of faster 
diffusion of the lighter Ba isotopes. Subsequently, the source reservoir becomes isotopically heavier with time.

Fig. 4. Fit of experimental concentration and isotope data of the $1.0 \mathrm{M} / 10^{\circ} \mathrm{C}$ diffusion experiment with the diffusive transport model with $u=0.95$ with time. Measured and modelled data of the source reservoir are shown on the left hand side, data of the sink on the right hand side. 2 sd uncertainties of concentration data are smaller than symbol size. Three scenarios were modelled: (1) diffusion without adsorption (solid lines), (2) diffusion plus linear adsorption of maximum $5.6 \times 10^{-5}$ moles ${ }^{137} \mathrm{Ba}$ and saturation of the gel surface after about 100 days (blue dashed lines), (3) and diffusion plus adsorption of $1.6 \times 10^{-4}$ moles ${ }^{137} \mathrm{Ba}$ (grey dashed lines). The total Ba concentration (b) and the concentration of ${ }^{134} \mathrm{Ba}$ and ${ }^{137} \mathrm{Ba}$ (d) in the sink reservoir are fitted well when neglecting adsorption. Allowing adsorption, the model underestimates the Ba concentrations in the sink. The concentrations in the source reservoir (a, c) are overestimated by the diffusion model for $t \leq 80$ days for scenarios (1) and (2). In scenario (3) data fit can be improved for the first 40 days, whilst data for $t>40$ days are highly underestimated. The model fits of the $\mathrm{Ba}$ isotopic composition of source and sink (e, f) agree well with the experimental data in all three scenarios.

Fig. 5. Ba concentration data of the $1.0 \mathrm{M} / 10{ }^{\circ} \mathrm{C}$ diffusion experiment fitted with the diffusive transport model with varying values for porosity $(\phi)$ and tortuosity $(\tau)$ of the silica hydrogel, summarised as $u=\phi^{*} \tau$. (a) Data fit of the source slightly improves with lower values for $u$. At the same time, the effective diffusion coefficient has to increase. (b) Evolution of the Ba concentration in the sink reservoir is independent of $u$, resulting in identical concentration profiles. 
Fig. 6. Effective diffusion coefficients extracted from the diffusive transport model with adsorption (white symbols) and without (grey/black symbols). The effective diffusivities correlate positively with temperature and $\mathrm{BaCl}_{2}$ concentration. Reference salt diffusion coefficients of $0.1 \mathrm{M}$ and $1.0 \mathrm{M} \mathrm{BaCl}_{2}$ solutions at $25^{\circ} \mathrm{C}$ were taken from Robinson and Stokes (2002). For other temperatures, diffusion coefficients were extrapolated (solid lines) using the Stokes-Einstein equation (Li and Gregory, 1974) with water viscosity data from Robinson and Stokes (2002).

Fig. 7. Ba isotopic composition of the sink reservoir of the $1.0 \mathrm{M} / 10{ }^{\circ} \mathrm{C}$ diffusion experiment fitted with different values for $\beta$. All data fall within a range of \pm 0.002 (grey area), which is taken as estimated uncertainty of $\beta$.

Fig. 8. Plot of $\beta$ values of alkali and alkaline earth metals against diffusivity. $\beta$ values were either experimentally derived (diamonds; Bourg et al., 2010; Richter et al., 2006) or calculated by MD simulations (circles; Bourg et al., 2010). Diffusion coefficients are for infinite dilution and $75^{\circ} \mathrm{C}$, calculated using the Stokes-Einstein equation with salt diffusion coefficients at $25^{\circ} \mathrm{C}$ and water viscosity data taken from Robinson and Stokes (2002). 

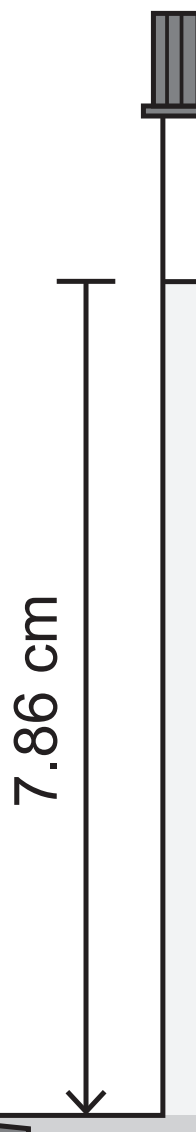

source

(5 $\mathrm{ml} \mathrm{BaCl}_{2}$ ) silica network

pores

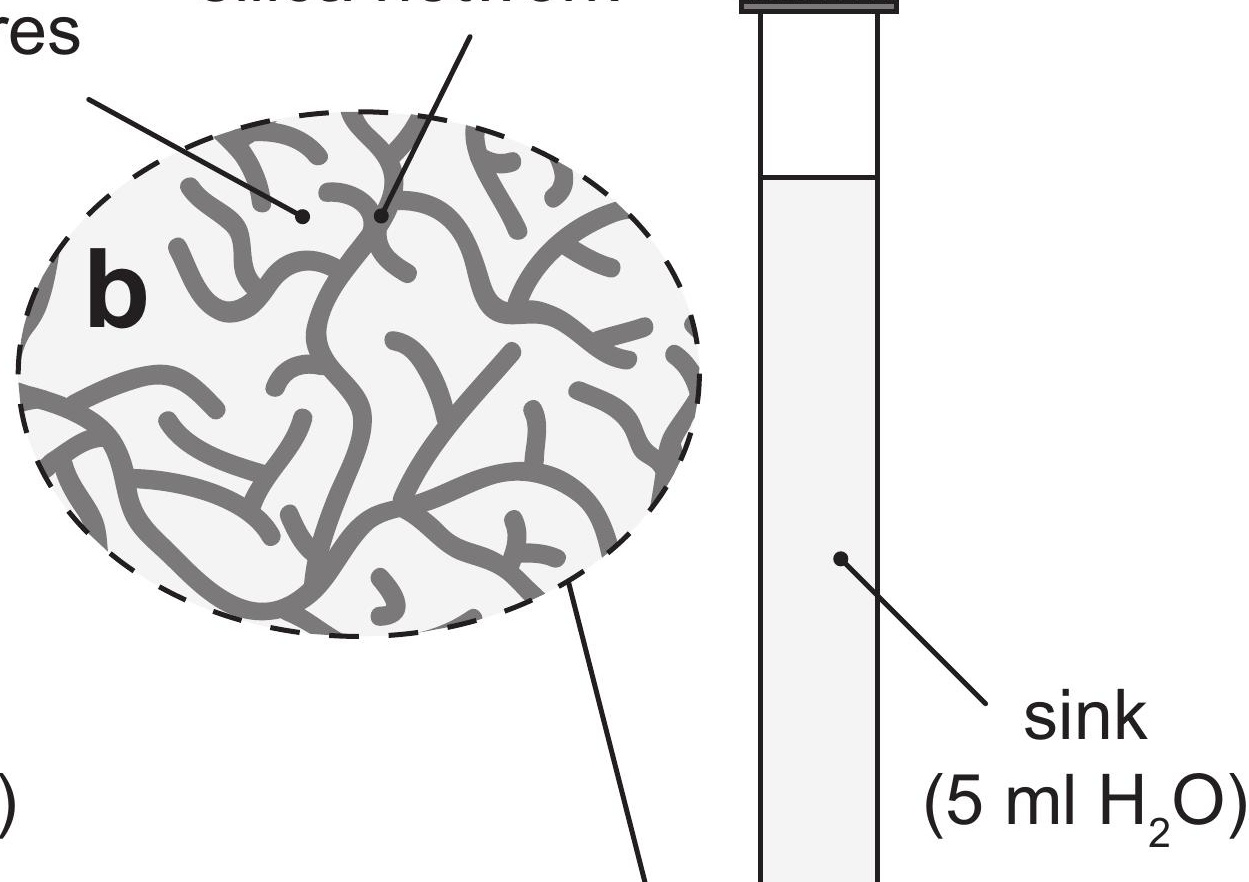

silica hydrogel $(9 \mathrm{ml})$

$\varnothing 0.9 \mathrm{~cm}$

$10 \mathrm{~cm}$

$14.15 \mathrm{~cm}$ 
Figure 3
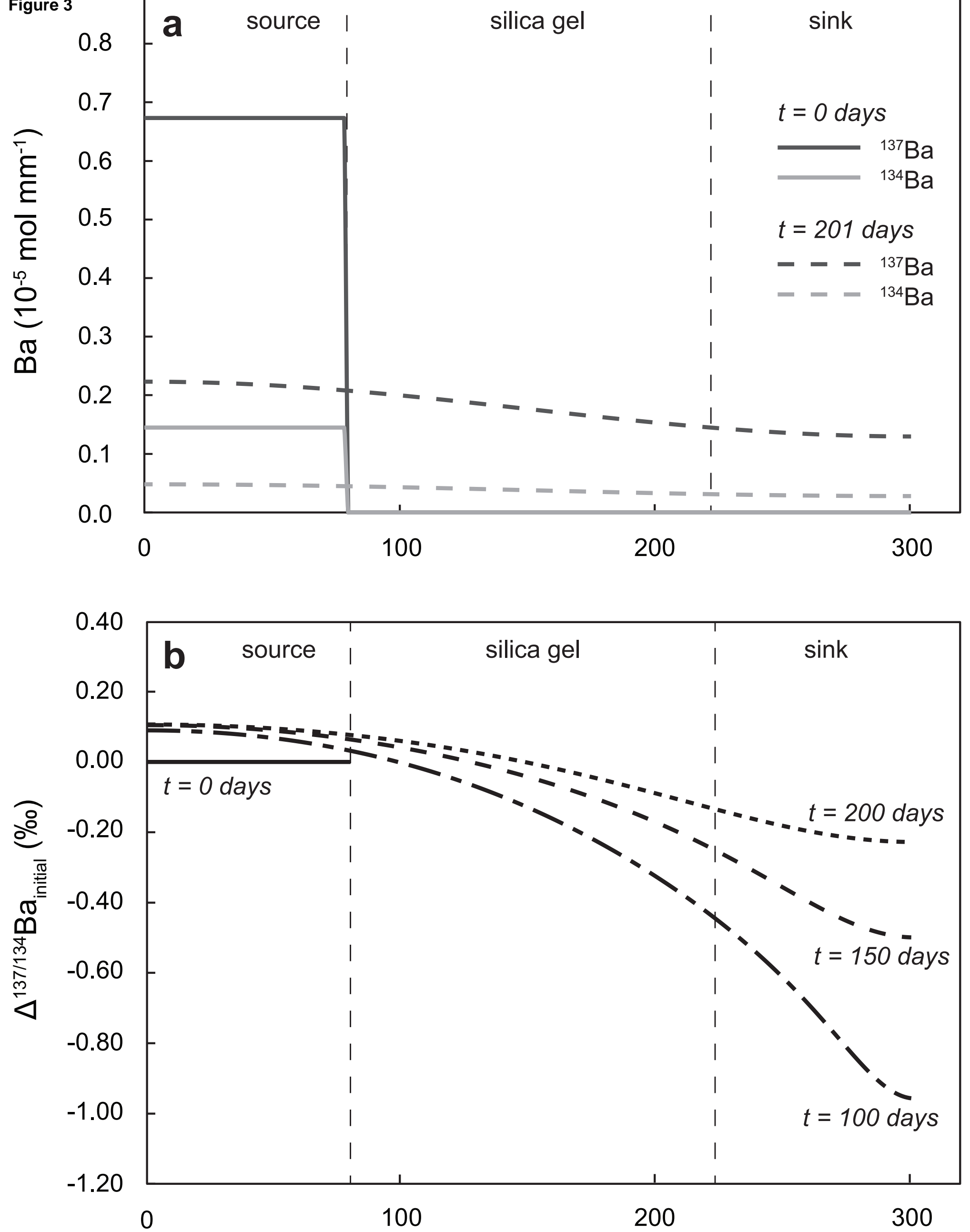

distance $(\mathrm{mm})$ 
Figure 4
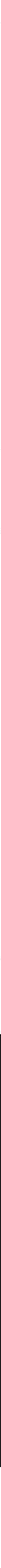
Figure $\$ 540$

a

120

80

60

40

$201.0 \mathrm{M}, 10^{\circ} \mathrm{C}$

source

80

क़
ठิ

๘

0

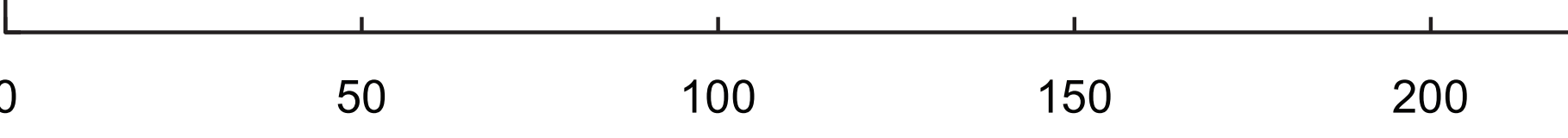

30

b

25

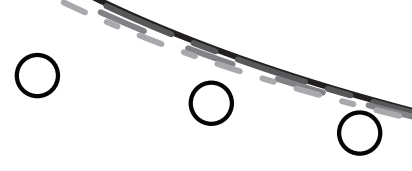

- - $-u=0.7, \quad D^{\text {eff }}=1.25^{*} 10^{-5}$

$=-n=-=\quad u=0.5, \quad D^{\text {eff }}=1.65^{*} 10^{-5}$
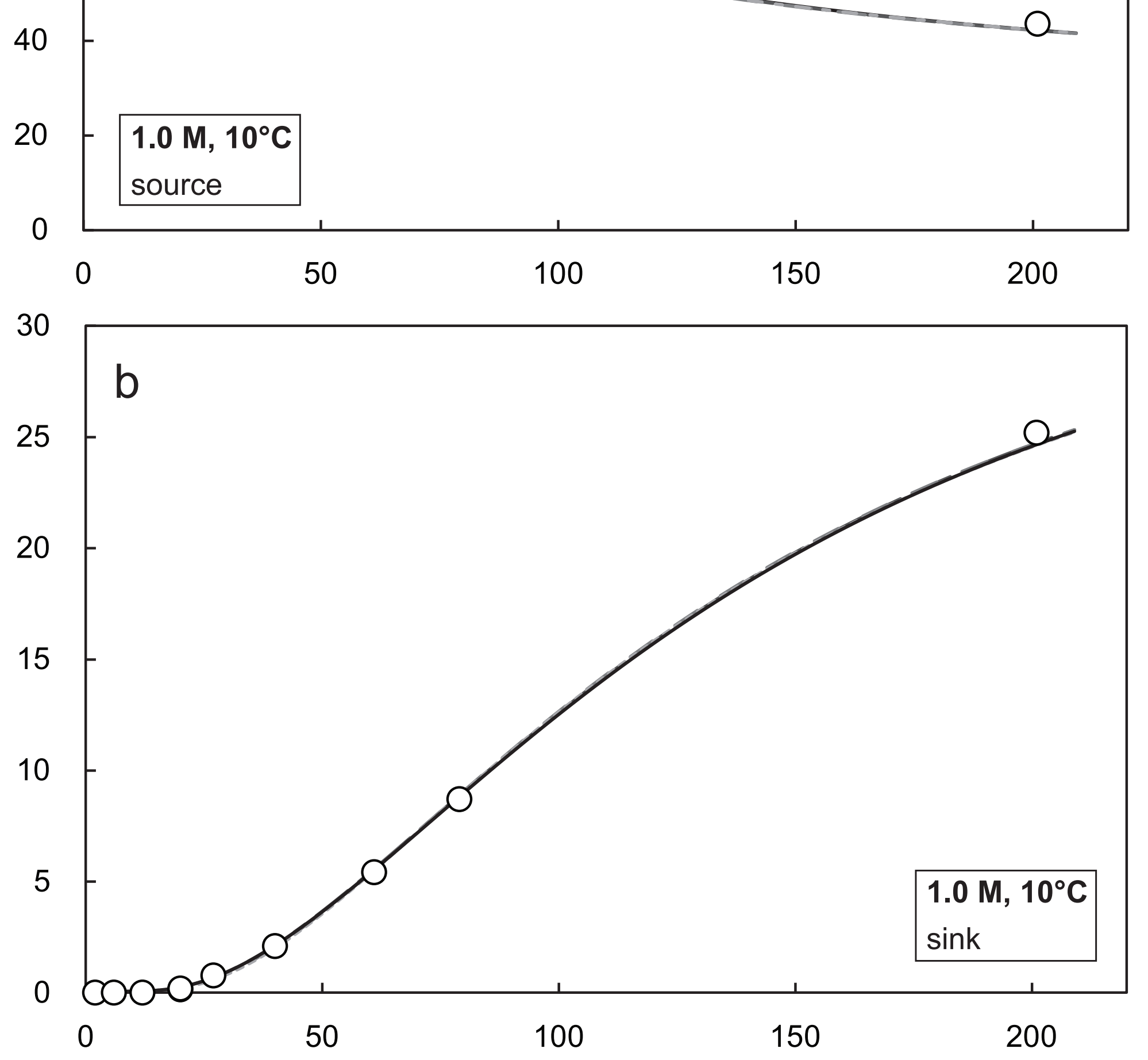

time (days) 
Figure 6

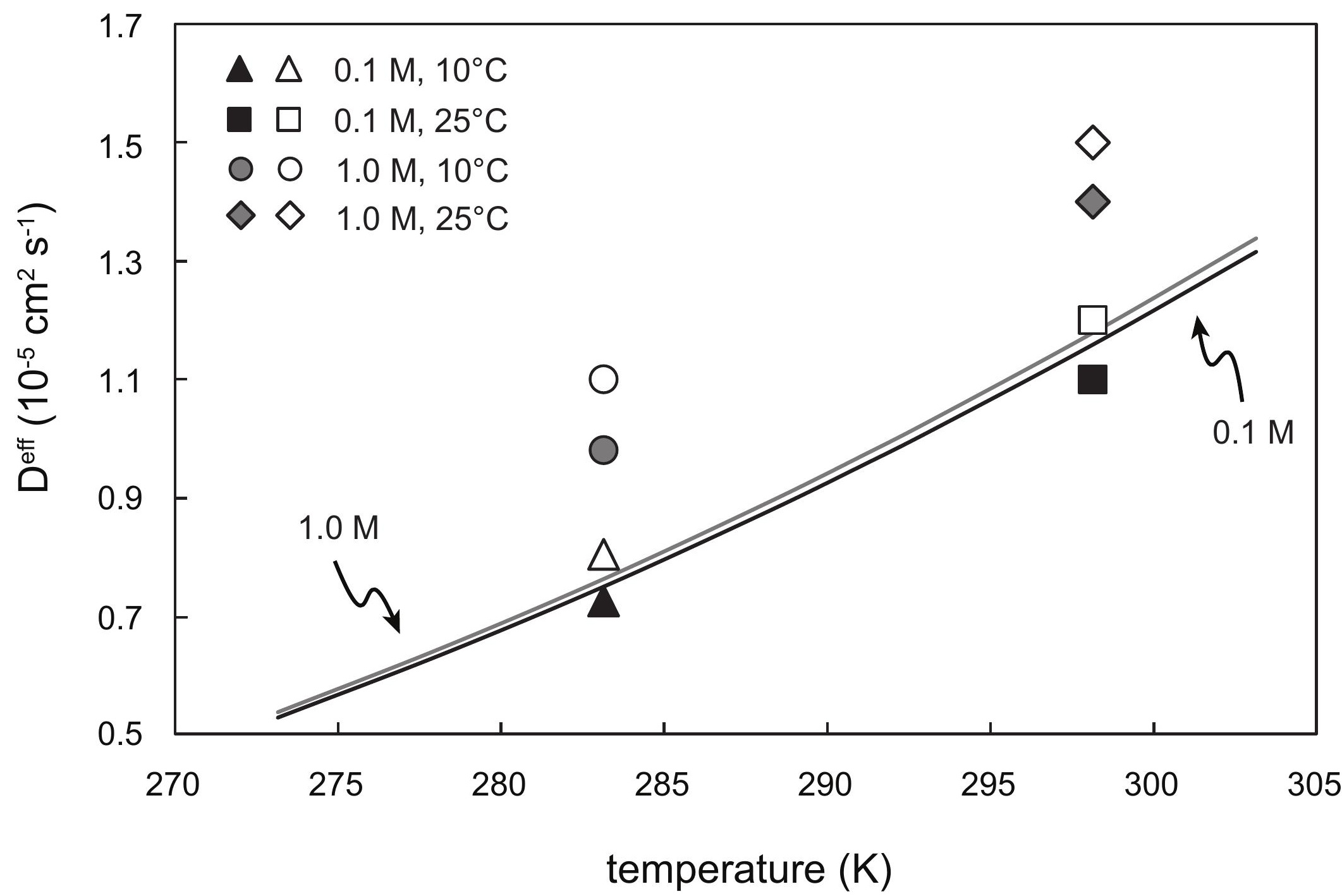




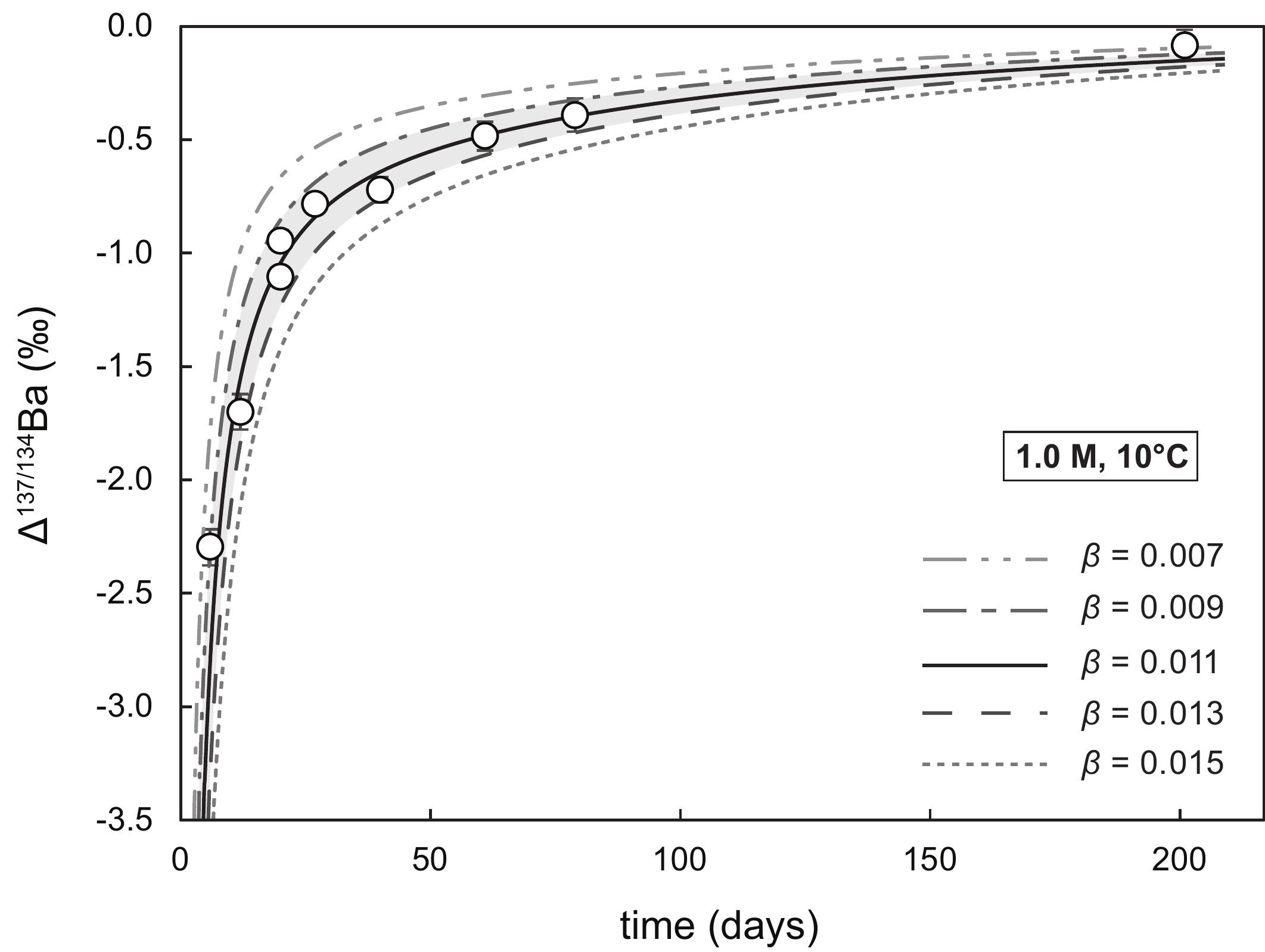


Figure 8

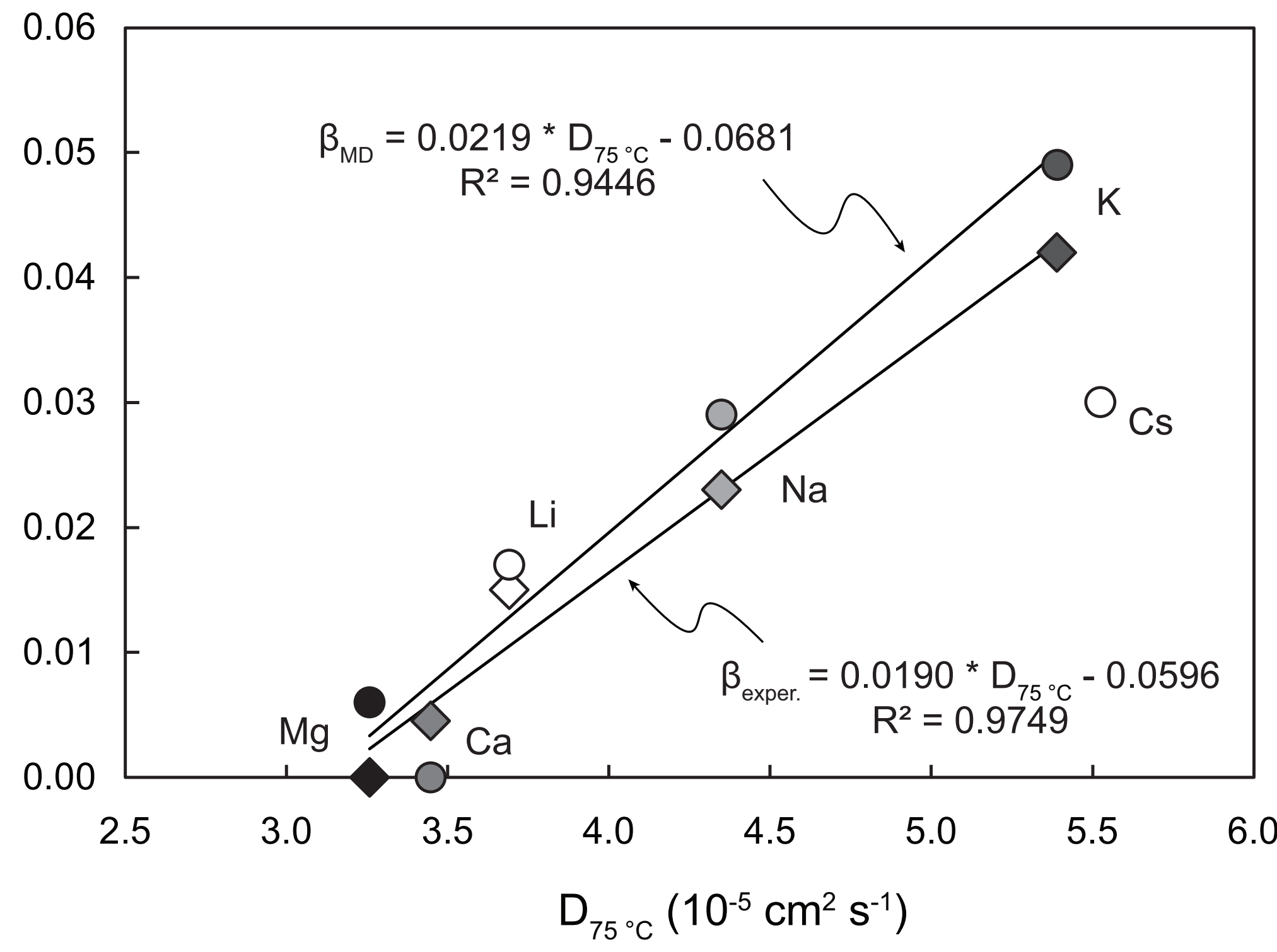

